\title{
Reaction mechanism of halogenated rubber crosslinking using a novel environmentally friendly curing system
}

\author{
Anna Dziemidkiewicz ${ }^{\mathrm{a}, *}$, Rafał Anyszka ${ }^{\mathrm{a}, \mathrm{b}}$, Anke Blume $^{\mathrm{b}}$, Magdalena Maciejewska ${ }^{\mathrm{a}}$ \\ ${ }^{a}$ Lodz Technical University, Institute of Polymer and Dye Technology, Stefanowskiego 12/16, 90-924, Lodz, Poland \\ ${ }^{\mathrm{b}}$ Elastomer Technology and Engineering, University of Twente, P.O. Box 217, 7500 AE, Enschede, the Netherlands
}

\section{A R T I C L E I N F O}

\section{Keywords:}

Heck-type reaction

Acetylacetonates

Crosslinking

Chloroprene rubber

Brominated butyl rubber

\begin{abstract}
A B S T R A C T
Iron (III) acetylacetonate (Fe (acac)) in the presence of triethanolamine (TEOA) was utilized as a novel crosslinking agent for halogenated diene rubber. Following the assumption that the mechanism of the crosslinking bases on the Heck-type reaction mechanism, which requires the presence of a halogen and an unsaturated carbon-carbon double bond, chloroprene rubber (CR) and brominated butyl rubber (BIIR) were utilized as rubber matrices. The results of FTIR spectra analysis confirm the proposed mechanism and indicate that a Heck-type reaction is feasible for performing a crosslinking of halogenated diene rubbers. The use of the Fe (acac)/TEOA curing system results in a significant torque increase during the vulcanization, which confirms the high activity of those compounds. The elimination of halogen from a rubber macromolecular structure or elimination of a basic environment of the crosslinking reaction results in a deactivation of the new curing system.
\end{abstract}

\section{Introduction}

More than four decades ago the palladium-catalyzed arylation reaction of olefin compounds with aryl iodides was discovered independently by Mizoroki [1] and Heck [2] (Scheme 1).

Nowadays, the Mizoroki-Heck or simply the Heck reaction has become one of the prime tools for carbon-carbon $(\mathrm{C}=\mathrm{C})$ double bond formations in organic syntheses [3-17]. It is one of the most studied coupling reactions and a great number of articles, reviews and books have been published about this topic [3,15]. It provides a basis for the synthesis of a variety of important compounds used in many areas, such as pharmaceuticals $[3,5,7,8,10,12,13,16]$ (spanning complex natural product synthesis, drug discovery and manufacturing or synthesis of taxol, one of the active anticancer drugs $[7,15])$, agrochemicals $[3,5,12$, $13,16]$, drug intermediates [7,8], antioxidants and UV absorbers $[7,8]$. Moreover, five commercial products have been identified that are produced by using the Heck reaction on a half-technological scale in excess of 1 ton per year [16].

However, despite its wide application the Heck-type reaction has not been used in the rubber industry so far. Preliminary research conducted at the Institute of Polymer and Dye Technology (Lodz University of Technology, Poland) [18-22] confirmed that metal complexes are active crosslinking agents for halogenated diene rubbers, which probably act via Heck-type reaction, and the vulcanizates obtained exhibit a high value of the crosslinking degree and good mechanical properties. However, the mechanism behind these curing reactions remains not confirmed. Due to the high reactivity and small amount of crosslinking agent, the application of metal complexes can offer new possibilities to the rubber industry for halogenated rubbers.

Originally, the Heck-type reaction refers to the reaction of a partially substituted alkene with an electrophile, such as halides, triflates, tosylates, mesylates, and diazonium salts, in the presence of a base (B) and a Pd catalyst, which results in a more substituted alkene [15]. Initially aryl, benzyl, and vinyl halides were used as the electrophiles. Latterly, many alkyl compounds have been employed for this purpose. The leaving groups are not limited to halides. Various sulfonates (such as triflates [13,16], mesylates, and tosylates), carboxylic derivatives [15], sulfonyl chlorides, diazonium salts [3,16], and iodonium salts have also been utilized in the Heck-type reaction [15]. This versatile reaction allows an effective $\mathrm{C}=\mathrm{C}$ bond formation at an unfunctionalized olefin carbon, in a single transformation, employing a wide variety of aryl and vinyl halide substrates. Originally, electron-poor alkenes such as acrylic esters were mostly employed but afterwards it was found that electron-rich alkenes, such as enolethers and non-polar olefins (including ethylene), could also be used in a Heck-type C-C cross-coupling reaction [15]. Unlike other C-C bond-forming reactions

\footnotetext{
* Corresponding author.

E-mail address: anna.dziemidkiewicz@edu.p.lodz.pl (A. Dziemidkiewicz).
} 


\section{$\mathrm{R}^{1} \mathrm{X}+\widehat{\wedge} \mathrm{R}^{2} \underset{\text { base }}{\stackrel{\mathrm{Pd}}{\longrightarrow}} \mathrm{R}^{1} \boldsymbol{\sim} \mathrm{R}^{2}+$ base $/ \mathrm{HX}$}

Scheme 1. Mechanism of Heck reaction with a Pd complex as a catalyst, where $\mathrm{R}_{1}, \mathrm{R}_{2}=$ aryl or alkyl and $\mathrm{X}=\mathrm{I} / \mathrm{Br} / \mathrm{Cl} /$ triflate (based on [15]).

that involve a polar addition, the Heck reaction tolerates almost any sensitive functionality, such as unprotected amine, hydroxyl, aldehyde, ketone, carboxyl, ester, cyano, and nitro groups [17].

The catalyst is an essential part of a Heck-type reaction, therefore different metal complexes consisting of a variety of metals and ligands has been studied as an alternative to the Pd catalysts [3]. The catalytic efficiency of transition-metal complexes depends strongly on the nature of their ligands and the donor groups and thus a choice of a proper ligand is essential to improve the catalytic performance [8]. However, owing to the sensitivity of ligands to air and moisture, to their toxicity, to their high price, to their non-recoverability and severe synthesis reaction conditions, a ligand-free Heck reaction has been developed [5, 17]. Simple palladium compounds, such as palladium chloride or palladium acetate $\left(\mathrm{PdCl}_{2}\right.$ or $\left.\mathrm{Pd}(\mathrm{OAc})_{2}\right)$, have been increasingly used for the Heck reaction due to their low costs [5]. For example, $\mathrm{Pd}(\mathrm{OAc})_{2}$ may be used as a catalyst without any ligand. However, it has to be reduced in situ to a Pd (0) species, which initiates the catalytic cycle. Some reagents of the Mizoroki-Heck reaction may play the role of reducing agents, such as amines used as bases [4].

$\mathrm{Pd}(\mathrm{OAc})_{2}$ has been originally used only as a convenient and inexpensive source of palladium and its role as an active catalyst has not been fully appreciated. Except when the more reactive aryl iodides are used as the electrophile substrates for a synthesis catalyzed by $\mathrm{Pd}(\mathrm{OAc})_{2}$. However, Yao, Kinney, and Yang [17] reported that $\mathrm{Pd}(\mathrm{OAc})_{2}$ can act as an active catalyst, in the presence of a base, also for the coupling of aryl bromides (which are less reactive electrophilic molecules than aryl iodides) with terminal olefins. Both the base and the solvent were found to have a fundamental influence on the efficiency of the reaction, with $\mathrm{K}_{3} \mathrm{PO}_{4}$ and $\mathrm{N}$, $\mathrm{N}$-dimethylacetamide being the optimal base and solvent, respectively [17].

According to the proposed mechanism of a $\mathrm{Pd}(\mathrm{OAc})_{2}$ catalyzed Heck reaction (Scheme 2) [17], the first step is the formation of a transient palladacycle $\mathbf{I}$ by the reaction of $\operatorname{Pd}(\mathrm{OAc})_{2}$ with the olefin. The palladacycle $\mathbf{I}$ is expected to be able to undergo oxidative addition of the arylhalide (Ar-X), generating the $\mathrm{Pd}(\mathrm{IV})$ species II. Base-promoted elimination of the acetate ion gives intermediate III, which subsequently reacts to the $\mathrm{Pd}(\mathrm{II})$ species IV by the release of the coupling

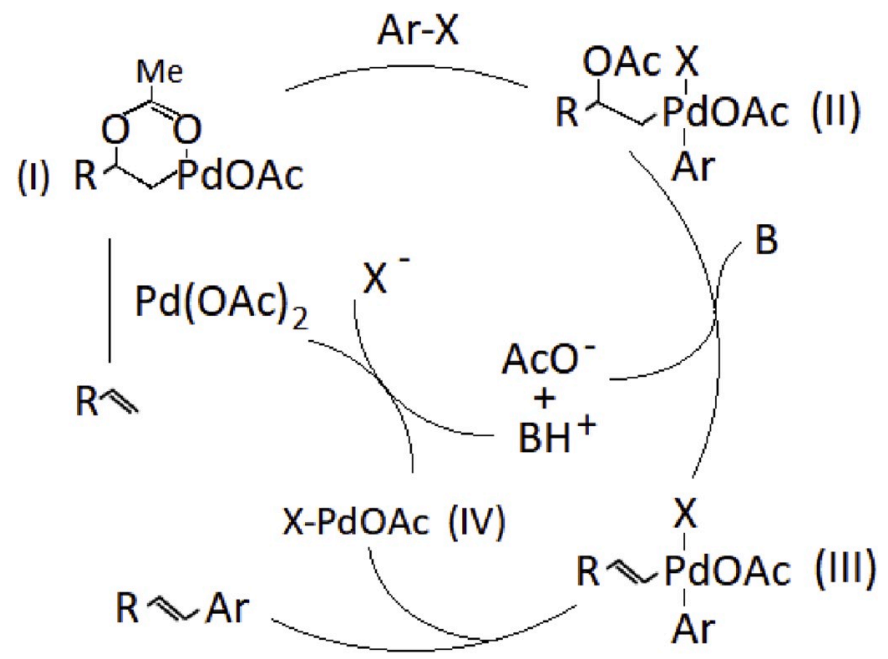

Scheme 2. The mechanism of the Heck reaction catalyzed by $\mathrm{Pd}(\mathrm{OAc})_{2}$ proposed by Yao et al. $\mathrm{Pd}(\mathrm{OAc})_{2}$ - palladium (II) acetate, ArX - aryl halide, B base [17]. product. Equilibration of IV with the acetate ion then regenerates Pd $(\mathrm{OAc})_{2}$. Additionally, IV itself could participate in the catalytic cycle in a similar way to that of the first turnover [17].

Among transition-metal catalysts, palladium catalysts exhibit excellent performance. Palladium is usually the preferred metal as it tolerates a wide variety of functional groups [3]. However, there is a growing interest in using less expensive transition metal catalysts comparing to Pd complexes $[8,15]$. In recent years, scientists have made great efforts to investigate low-cost transition-metal catalyzed Heck-type reactions and have achieved promising results $[8,9,15]$. Wang and Yang discussed both homogeneous and heterogeneous catalytic systems containing $\mathrm{Ni}$, $\mathrm{Co}, \mathrm{Cu}$ or $\mathrm{Fe}$ based catalysts, which were found to be active for Heck-type reaction as well.

The aim of this study was to verify if the Heck reaction could be used for the crosslinking of halogenated diene rubbers. The vulcanization (crosslinking or curing) is one of the most essential processes in the rubber technology. It allows the conversion of a raw material into final rubber products exhibiting desired physical, chemical and mechanical performance. All of the known methods of halogenated diene rubbers vulcanization exhibit some disadvantages- application of potentially carcinogenic or harmful chemical compounds or insufficient properties of the obtained vulcanizates [23]. Because of this, researchers are still looking for new methods of vulcanization leading to an enhancement of the final product properties. It is crucial to design a curing system that leads to the preparation of vulcanizates with good functional properties, relatively short vulcanization time and exhibiting an environmentally friendly composition.

Preliminary studies, conducted at the Institute of Polymer and Dye Technology of the Lodz University of Technology in Poland [18-22] have shown that the greatest advantage of using metal acetylacetonates ( $\mathrm{Me}(\mathrm{acac})$ ) as a curing catalyst is that a high activity can be achieved with a very small amount of the curing agents. Moreover in comparison to standard used systems, the application of the proposed curing system allows to eliminate zinc oxide ( $\mathrm{ZnO}$ ), which exhibit aquatic toxicity and ethylene thiourea (ETU), which is classified as toxic for reproduction, with CMR risk assessment: Repr. Cat. 2, R61 - "May cause harm to the unborn child" [24]. The relatively low price of both metal complexes and TEOA combined with the low required amount, makes the proposed curing system economically more affordable than conventional metal oxide and sulfur based curing systems.

In this study, the activity of affordable (Fe (acac)) (Scheme 3) as curing agent for the vulcanization of CR and BIIR rubber based on the Heck-type reaction was examined. To ensure the alkaline environment of the reaction triethanolamine (TEOA) was applied. TEOA was also responsible for the regeneration of the catalyst by binding $\mathrm{HBr}$ or $\mathrm{HCl}$, which are produced during the crosslinking reaction.

Moreover, it should be noted that the presented curing system for CR and BIIR vulcanization is an entirely new approach and has not been described in the literature so far. Therefore, it is important to study the mechanism of the reaction, which is crucial for further optimization of the crosslinking process and properties of vulcanizates.

\section{Experimental}

\subsection{Materials}

Iron (III) acetylacetonate $97 \%$ (Fe (acac)) was used as an active catalyst in the presence of triethanolamine $98 \%$ (TEOA) in order to ensure an alkaline environment for the crosslinking process. Fe (acac) and TEOA were purchased from Sigma Aldrich (St. Louis, US). As rubber matrices mercaptan-modified CR (Denka M-40) and BIIR (BIIR-2302) with $1.9 \pm 0.2 \%$ of bromination were applied. CR and BIIR were provided by Torimex-Chemicals (Konstantynow Lodzki, Poland). All chemicals were used as received without further purification. 


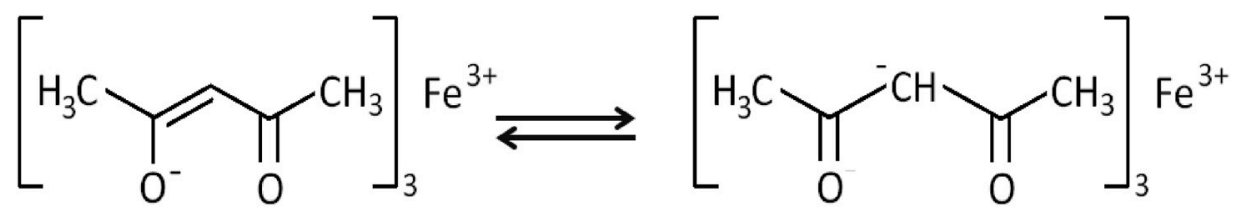

Scheme 3. Structure of the iron (III) acetylacetonate.

\subsection{Preparation and characterisation of rubber compounds}

Preparation of the rubber compounds was the first step of work. CR or BIIR compounds filled with increasing amount ( $0-1 \mathrm{phr})$ of $\mathrm{Fe}$ (acac) or with $\mathrm{Fe}$ (acac) in the presence of TEOA or with TEOA itself were prepared (Table 1a and Table $1 \mathrm{~b}$ ). All the curing compositions are presented as parts per hundred parts of rubber (phr). The mixing procedure was carried out inside the internal mixer Brabender Plasticorder PL2000 (Duisburg, Germany) maintained at $50{ }^{\circ} \mathrm{C}$.The mixing procedure was carried out as presented in Table 2.

The kinetics of the vulcanization was determined at $160{ }^{\circ} \mathrm{C}$ by the RPA 2000 rubber process analyzer from Alpha Technologies (Bellingham,WA, USA). The vulcanization (at $160{ }^{\circ} \mathrm{C}$ ) was carried out using a hydraulic press with electrical heating.

The degree of crosslinking ( $\alpha$ ) of vulcanizates was determined based on the solvent-swelling measurements in toluene and was calculated from equation (1):

$\alpha=1 / \mathrm{Q}_{\mathrm{v}}$

where: $\mathrm{Q}_{\mathrm{v}}$ - volume swelling determined based on equation (2):

$\mathrm{Q}_{\mathrm{v}}=\mathrm{Q}_{\mathrm{w}} \cdot \rho_{\mathrm{r}} / \rho_{\mathrm{s}}$

where: $Q_{w}$ - equilibrium swelling determined using equation (3), $\rho_{r}$ rubber density $\left[\mathrm{g} / \mathrm{cm}^{3}\right], \rho_{\mathrm{s}}$ - solvent density $\left[\mathrm{g} / \mathrm{cm}^{3}\right]$

$\mathrm{Q}_{\mathrm{w}}=\left(\mathrm{m}_{\mathrm{sw}}-\mathrm{m}_{\mathrm{d}}\right) / \mathrm{m}_{\mathrm{d}}$

where: $\mathrm{m}_{\mathrm{sw}}$ - the weight of swollen sample $[\mathrm{mg}], \mathrm{m}_{\mathrm{d}}$ - the weight of dried sample after swelling [mg].

Fourier transform infrared spectroscopy (FTIR) was performed by means of PerkinElmer Spectrum 100 series (Waltham, US) equipped with attenuated total reflection ATR device, which enables to test samples in the solid or liquid state without prior preparation. Data collection was performed over the wavelength range from 4000 to 650 $\mathrm{cm}^{-1}$ with a resolution of $0.5 \mathrm{~cm}^{-1}$.

Differential scanning calorimetry (DSC) was carried out by means of Mettler Toledo DSC1 (Greifensee, Switzerland) to study the temperature and enthalpy of the vulcanization. Data collection was performed in a temperature range of $-100{ }^{\circ} \mathrm{C}$ to $250{ }^{\circ} \mathrm{C}$ with a heating rate of $10{ }^{\circ} \mathrm{C}$ / min.

For the study of the dispersion of the catalyst a scanning electron

Table 1a

General compositions of the CR - based rubber compounds.

\begin{tabular}{llll}
\hline Compound description & rubber [phr] & TEOA [phr] & Fe (acac) [phr] \\
\hline CR & 100 & - & - \\
CR, 0.05 Fe & 100 & - & 0.05 \\
CR, 0.1 Fe & 100 & - & 0.1 \\
CR, 0.2 Fe & 100 & - & 0.2 \\
CR, 0.3 Fe & 100 & - & 0.3 \\
CR, 0.4 Fe & 100 & - & 0.4 \\
CR, 0.5 Fe & 100 & - & 0.5 \\
CR, 0.6 Fe & 100 & - & 0.6 \\
CR, 0.7 Fe & 100 & - & 0.7 \\
CR, 0.8 Fe & 100 & - & 0.8 \\
CR, 0.9 Fe & 100 & - & 0.9 \\
CR, 1.0 Fe & 100 & 4 & 1.0 \\
CR, 0.1 Fe, 4TEOA & 100 & 4 & 0.1 \\
CR, 4TEOA & 100 & - \\
\hline
\end{tabular}

Table 1b

General compositions of the BIIR-based rubber compounds.

\begin{tabular}{llll}
\hline Compound description & BIIR [phr] & TEOA [phr] & Fe (acac) [phr] \\
\hline BIIR & 100 & - & - \\
BIIR, 0.05 Fe & 100 & - & 0.05 \\
BIIR, 0.1 Fe & 100 & - & 0.1 \\
BIIR, 0.2 Fe & 100 & - & 0.2 \\
BIIR, 0.3 Fe & 100 & - & 0.3 \\
BIIR, 0.4 Fe & 100 & - & 0.4 \\
BIIR, 0.5 Fe & 100 & - & 0.5 \\
BIIR, 0.6 Fe & 100 & - & 0.6 \\
BIIR, 0.7 Fe & 100 & - & 0.7 \\
BIIR, 0.8 Fe & 100 & - & 0.8 \\
BIIR, 0.9 Fe & 100 & - & 0.9 \\
BIIR, 1.0 Fe & 100 & - & 1.0 \\
BIIR, 0.1 Fe, 4 TEOA & 100 & 4 & 0.1 \\
BIIR, 4 TEOA & 100 & 4 & - \\
\hline
\end{tabular}

Table 2

Rubber mixing procedure.

\begin{tabular}{ll}
\hline Time $[\mathrm{min}]$ & Action \\
\hline 0 & Rubber addition and mixing with closed ram \\
3 & Addition of Fe (acac) or Fe (acac)/TEOA \\
5 & Mixing with closed ram \\
10 & Removal of prepared rubber compound \\
\hline
\end{tabular}

${ }^{\text {a }}$ For compounds with Fe (acac)/TEOA system the mixing procedure was 5 min longer because of the difficulties in incorporating TEOA.

microscope (SEM) Jeol JSM-6400 (Tokyo, Japan) configured with a Noran energy dispersive X-ray analyzer (EDS) and 3D Laser Scanning Confocal Microscope Keyence VK-X (Mechelen, Belgium) were used.

\section{Results and discussion}

\subsection{The kinetics of vulcanization}

In order to investigate the activity of $\mathrm{Fe}$ (acac) as a crosslinking agent and the influence of TEOA on the activity of Fe (acac) and crosslinking process itself, kinetic studies of the vulcanization behavior of the rubber compounds with an increasing amount of $\mathrm{Fe}$ (acac), with $\mathrm{Fe}$ (acac) in the presence of TEOA or only with TEOA were performed. All results are presented in Figs. 1-4. Figs. 1 and 3 present the influence of different amounts (from 0 to $1 \mathrm{phr}$ ) of Fe (acac) on the cure behavior of CR and BIIR respectively. Figs. 2 and 4 demonstrate the influence of the presence of TEOA on the vulcanization reaction of CR and BIIR respectively. The difference between the maximum torque and the minimum torque (torque increment) was used as an indirect indication of the crosslink density of the vulcanizates [12].

All presented results (Figs. 1-4) indicate that Fe (acac) is an effective crosslinking agent for $\mathrm{CR}$ and BIIR rubbers. This was confirmed by the high values of the torque increment during the vulcanization of the compounds. Comparing the two investigated rubbers (CR and BIIR), a significantly higher torque increment and much shorter scorch time for all CR compounds containing Fe (acac) is observed. It is most likely related to a much higher halogenation and double bonds content in $\mathrm{CR}$ in comparison to BIIR. Moreover, the significant influence of TEOA on the activity of the proposed curing system is also evident for both CR and 


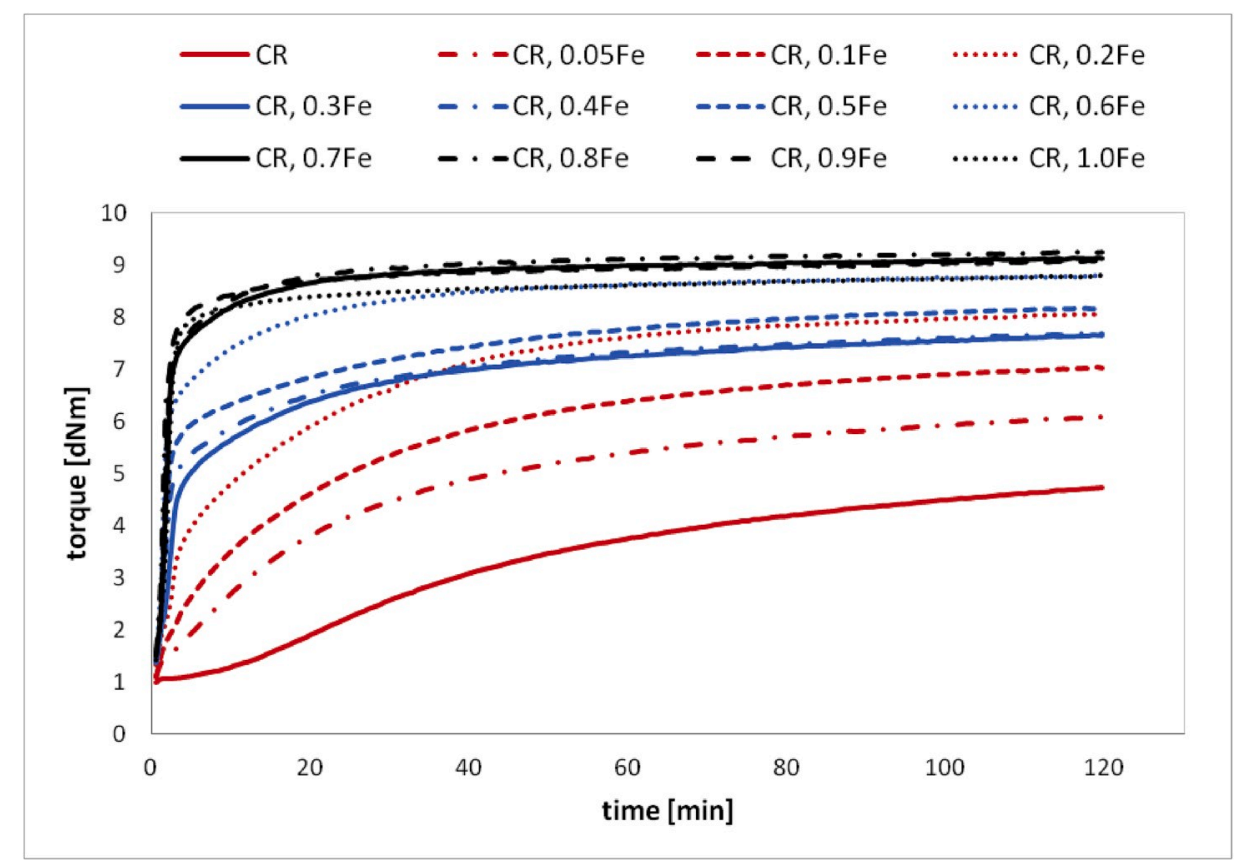

Fig. 1. The vulcanization kinetics of the CR compounds with increasing amount of Fe (acac).

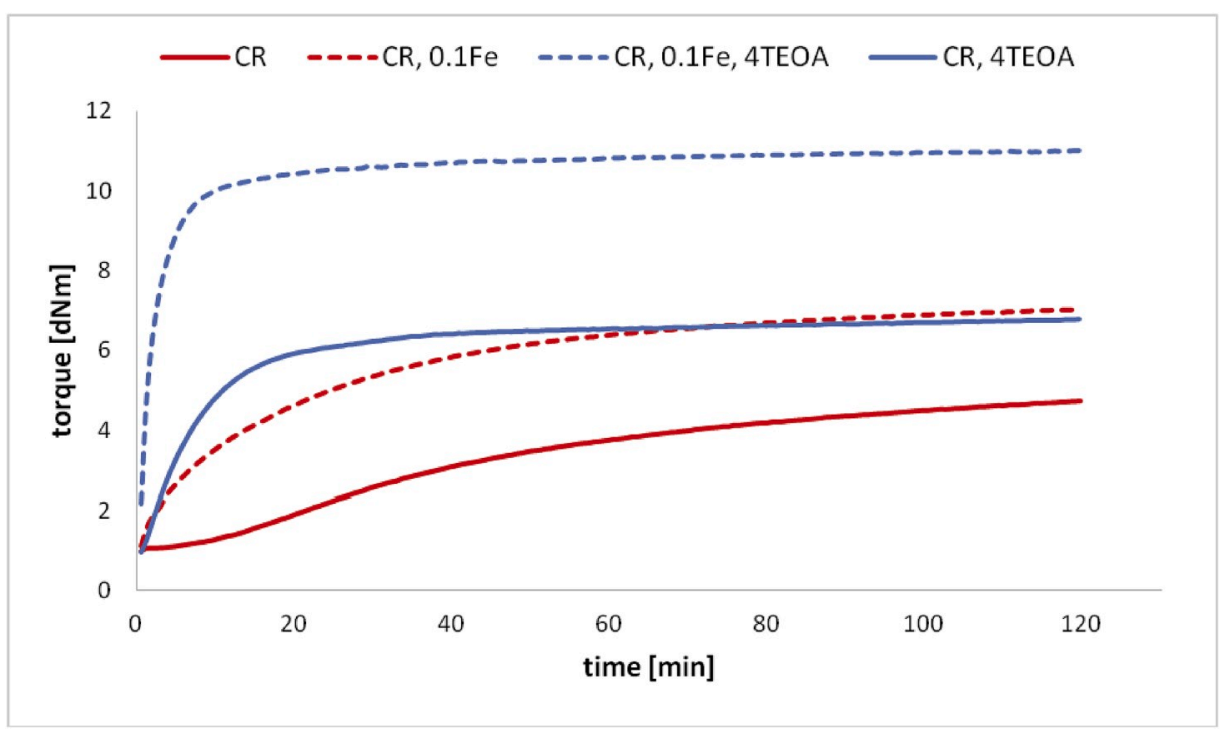

Fig. 2. The vulcanization kinetics of the CR compounds in the presence of TEOA.

BIIR.

From Fig. 1 it is concluded that CR undergoes a thermal crosslinking also without the addition of any catalyst, but an increasing quantity of Fe (acac) catalyst results in a higher torque increment during the vulcanization, which indicates a higher degree of crosslinking. The increase of the torque increment is not precisely connected with the increasing quantity of $\mathrm{Fe}$ (acac), which results from an insufficient dispersion and distribution of the curing agent clusters in the rubber matrix. To confirm this hypothesis and investigate the dispersion and distribution of the Fe (acac) in the CR rubber matrix, EDS analysis of the compound that contains $1 \mathrm{phr}$ of Fe (acac) was performed (Fig. 5). According to the images obtained, the dispersion of Fe (acac) in the CR can be stated as homogeneous only to some extent. The catalyst forms some bigger particles of a relatively high diameter $(6.25-31.25 \mu \mathrm{m})$. Due to this, only the molecules at the surface of the agglomerates can catalyze the crosslinking reaction effectively. Therefore, not only the amount of the $\mathrm{Fe}$ (acac) catalyst but also its dispersion and distribution influence the torque increament during the vulcanization. The increase of the torque increment is not perfectly precisely connected with the increasing quantity of $\mathrm{Fe}$ (acac) which is also true for BIIR. It also may be influenced by a poor dispersion and distribution state of Fe (acac) (Fig. 3).

Additionally SEM and EDS images of both CR and BIIR compounds containing $1 \mathrm{phr}$ of $\mathrm{Fe}$ (acac) confirm the presence of some bigger particles (Fig. 6 -Fig. 7). Fig. 6 indicates the presence of Fe (acac) clusters in chloroprene rubber with the maximum diameter of approximately 50 $\mu \mathrm{m}$. Whereas Fig. 7 reveals the presence of Fe (acac) clusters in brominated butyl rubber with the maximum diameter of approximately 68 $\mu \mathrm{m}$.

Furthermore, the dispersion and distribution of the curing agent were investigated by using a 3D Laser Scanning Confocal Microscope measurement (Fig. 8). More detailed analysis of the maximum diameter 


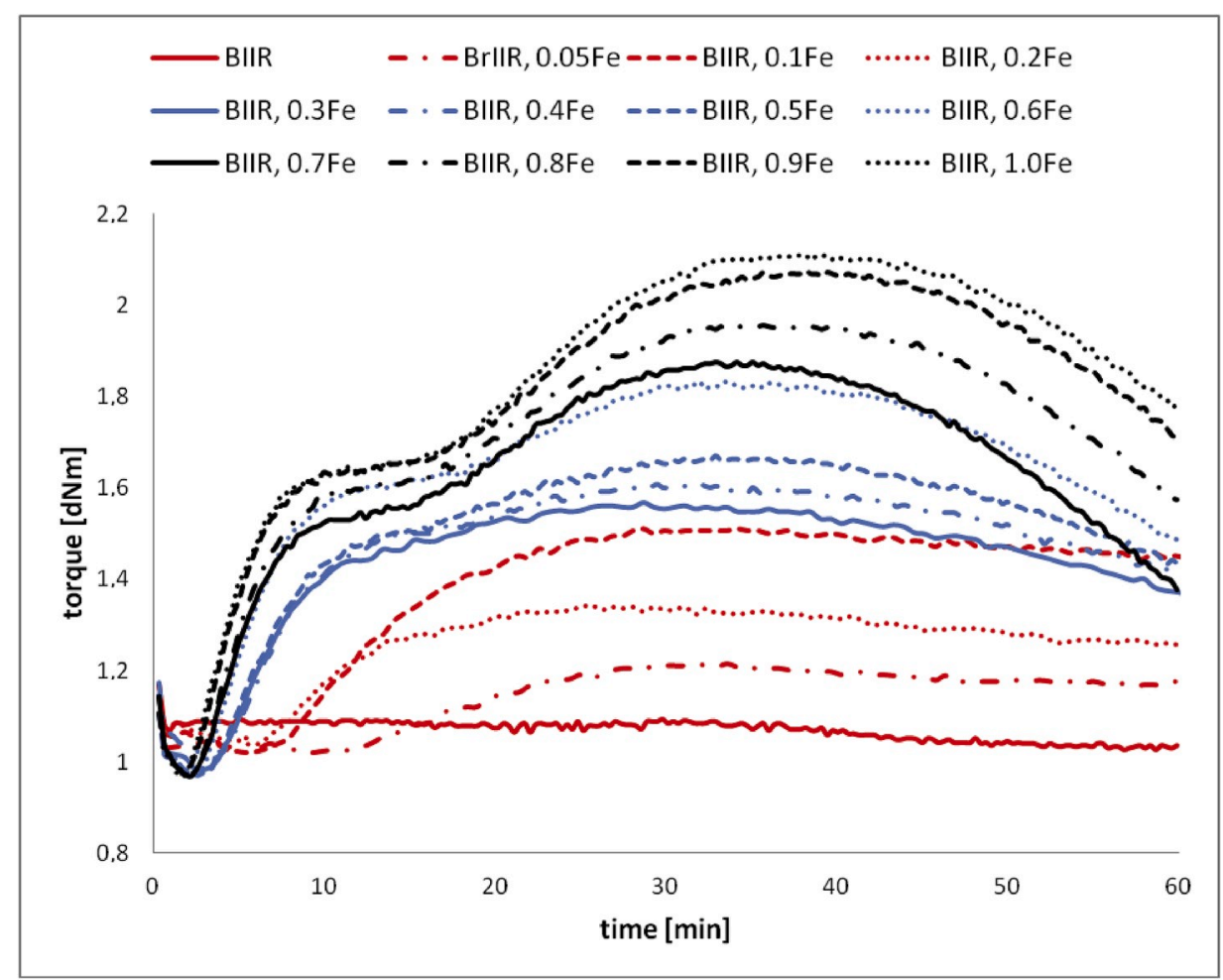

Fig. 3. The vulcanization kinetics of the BIIR compounds with increasing amount of Fe (acac).

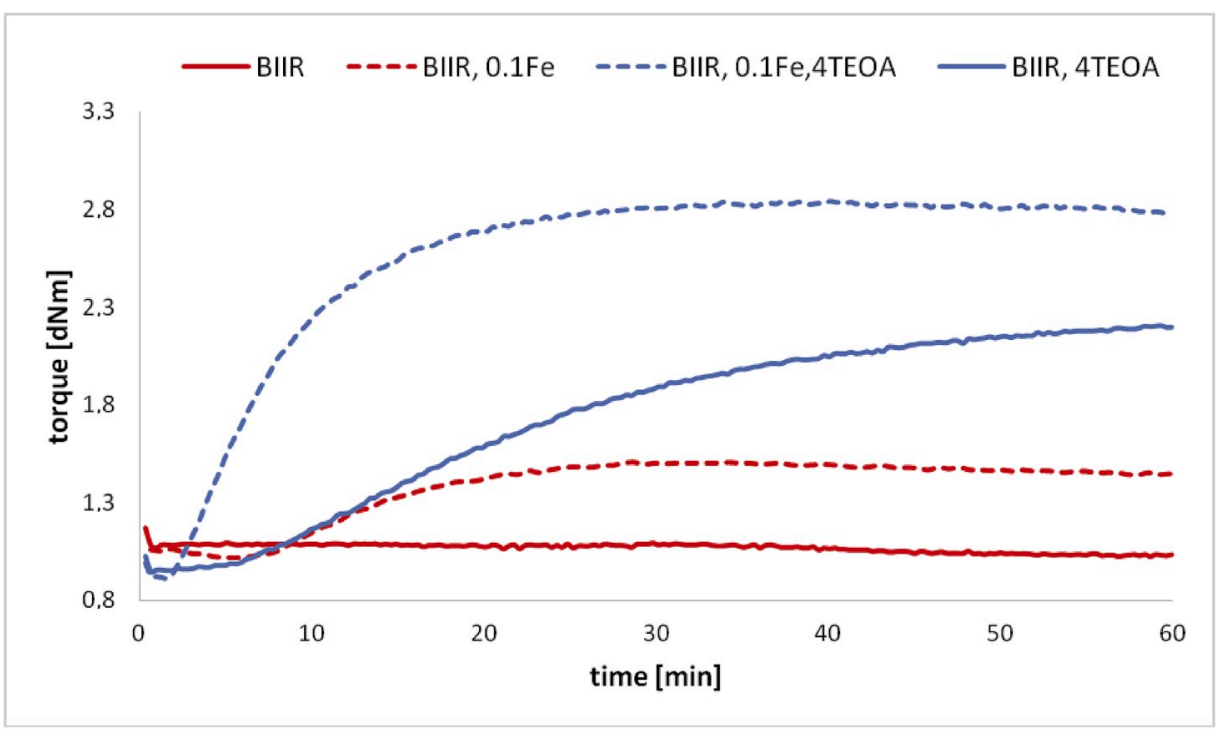

Fig. 4. The vulcanization kinetics of the BIIR compounds in the presence of TEOA.

of the Fe (acac) particles indicates the highest content of clusters containing a diameter from 15 to $40 \mu \mathrm{m}$ for both CR and BIIR vulcanizates (Fig. 9-Fig. 11).

The influence of TEOA on the vulcanization kinetics is presented in Figs. 2 and 4. It shows that an application of TEOA enhances the effectiveness of the proposed crosslinking system to a significant extent. The compounds containing $\mathrm{Fe}$ (acac) in the presence of TEOA exhibit the highest torque increment, even compared to compounds that contain a tenfold higher amount of Fe (acac) but in absence of TEOA. It indicates the great importance of TEOA in the reaction and confirms the hypothesis about the Heck reaction mechanism responsible for the crosslinking.
Moreover, the kinetic behavior of the vulcanization of the sample containing only TEOA (Fig. 2) indicates that perhaps in the case of CR two different mechanisms of crosslinking reaction take place. Due to the fact that CR can undergo a thermal curing [25], it can be supposed that TEOA bonds $\mathrm{HCl}$, which is produced during the thermal curing, making this process much more effective.

As shown in Fig. 3, BIIR cannot be crosslinked without the addition of the catalyst as opposed to CR. As already mentioned, BIIR contains a much lower amount of double bonds and halogen elements than CR, which seems to result in a much lower torque increment. Moreover, the rheometrical curves of the BIIR based compositions with a content of $\mathrm{Fe}$ (acac) exceeding $0.3 \mathrm{phr}$ show a two-step process of the vulcanization. 


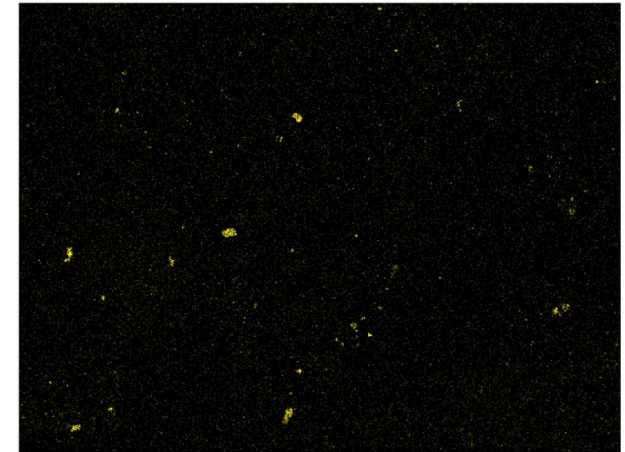

$250 \mu \mathrm{m}$

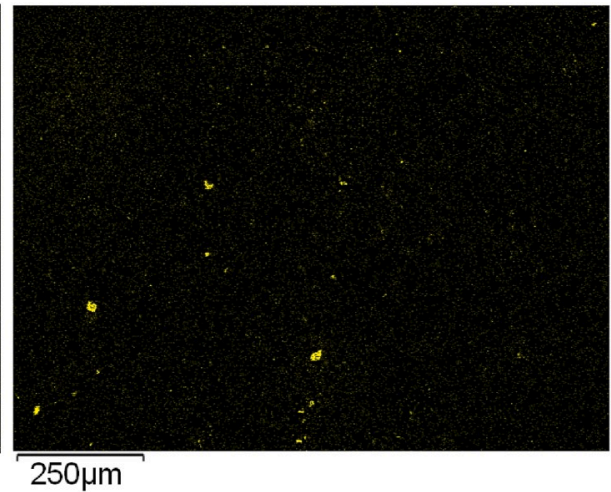

$250 \mu \mathrm{m}$

Fig. 5. EDS iron image (mapping) of CR compound containing 1 phr of Fe (acac).
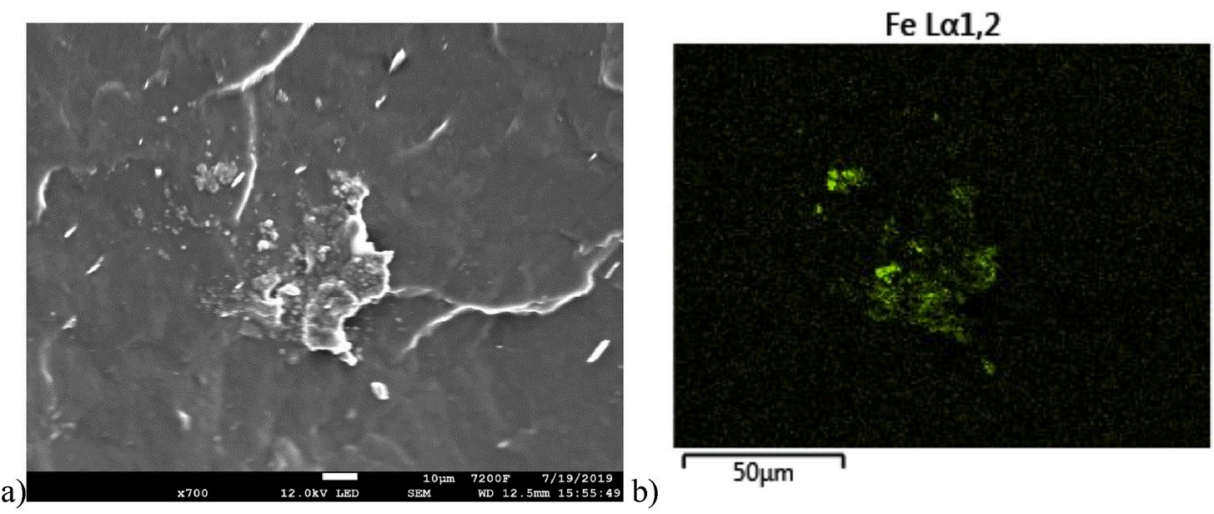

C K $\alpha 12$

\section{$\mathrm{Cl} K \alpha 1$}

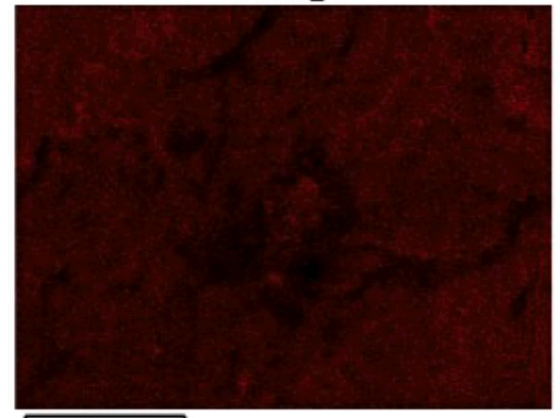

c)

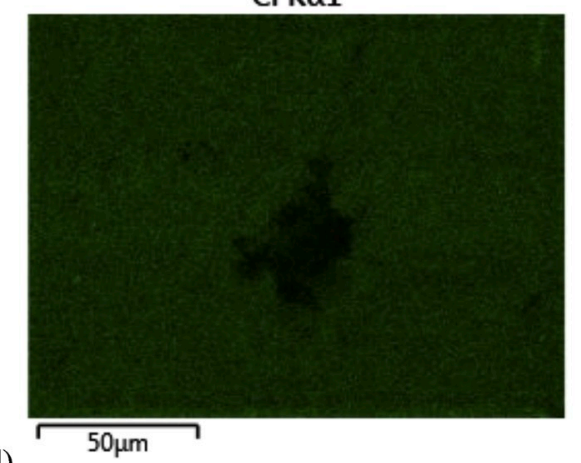

d)

Fig. 6. Morphology of an Fe (acac) agglomerate in chloroprene rubber filled with $1 \mathrm{phr}$ of Fe (acac) (a): iron (b), carbon (c) and chlorine (d) distribution maps done by SEM-EDS.

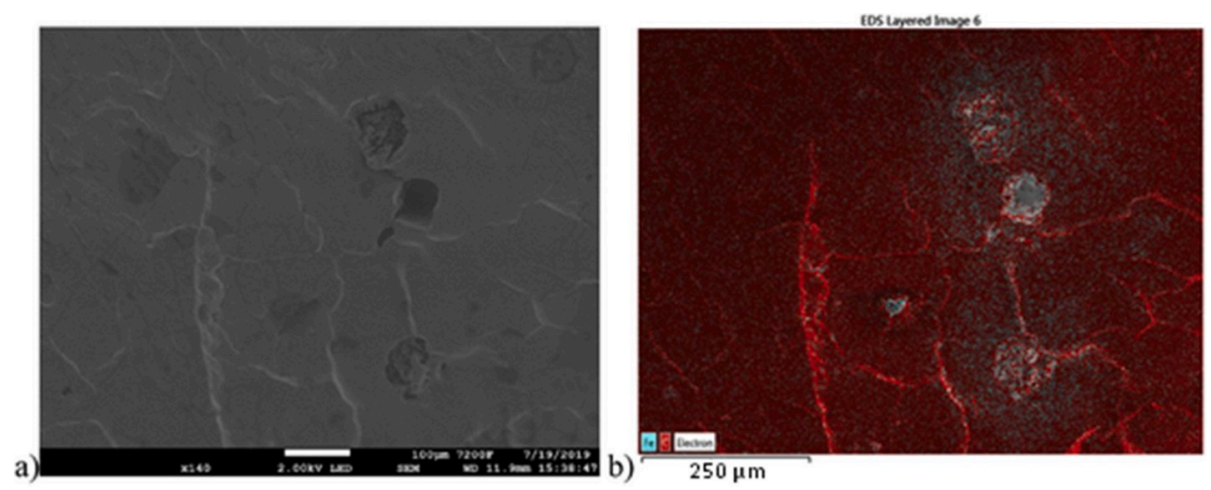

Fig. 7. SEM (a) and SEM-EDS mapping (b) of Fe (acac) clusters morphology in the BIIR vulcanizate filled with 1 phr of Fe (acac). 

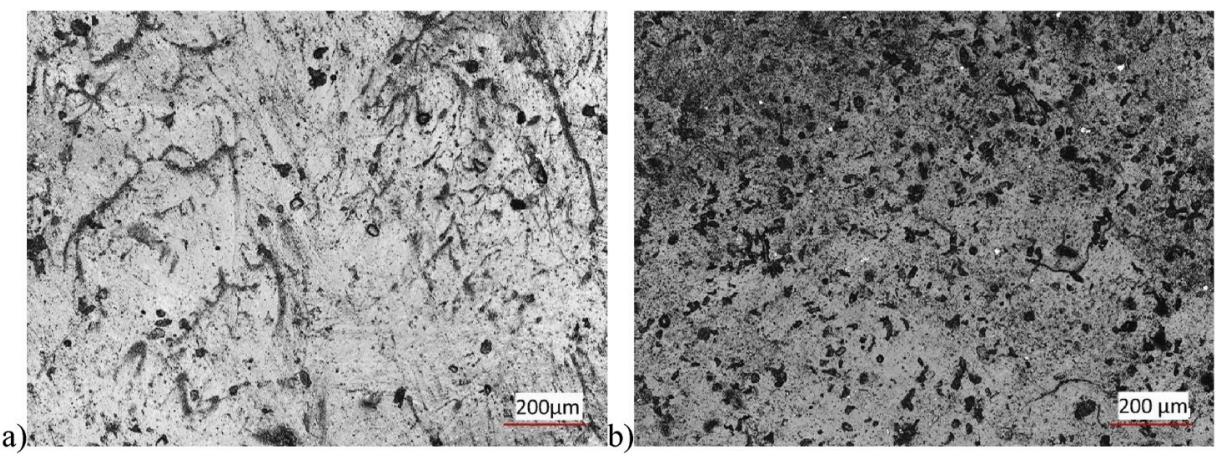

Fig. 8. Laser Scanning Confocal Microscope images of CR (a) or BIIR (b) vulcanizates filled with $1 \mathrm{phr}$ of Fe (acac).
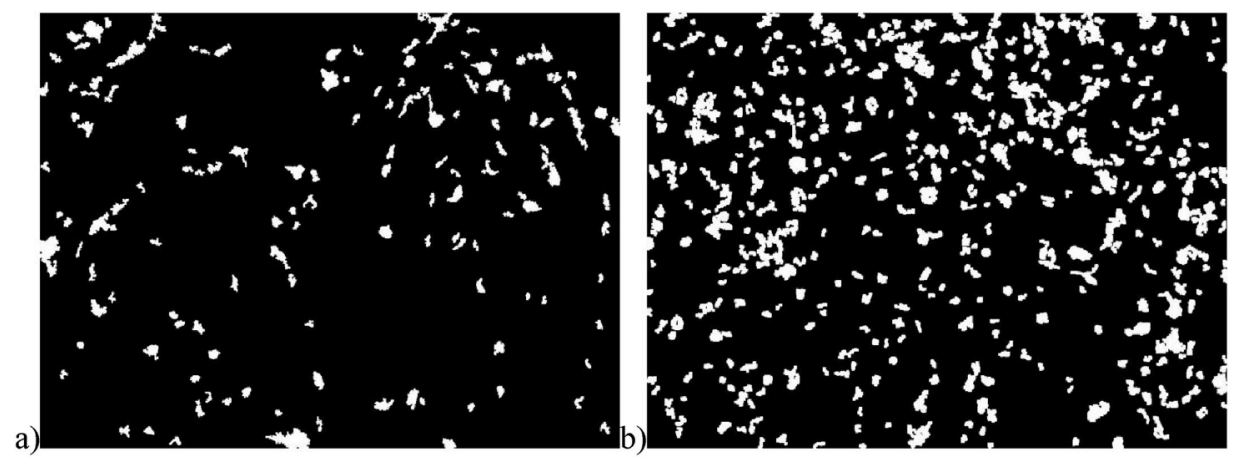

Fig. 9. Laser Scanning Confocal Microscope images of Fe (acac) clusters morphology in the CR (a) or BIIR (b) vulcanizate filled with 1 phr of Fe (acac).

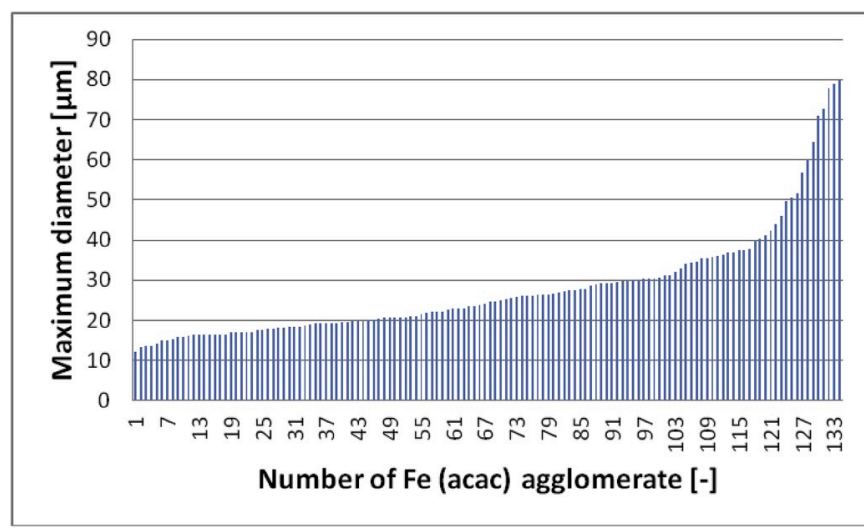

Fig. 10. Maximum diameters of Fe (acac) clusters in CR vulcanizates.

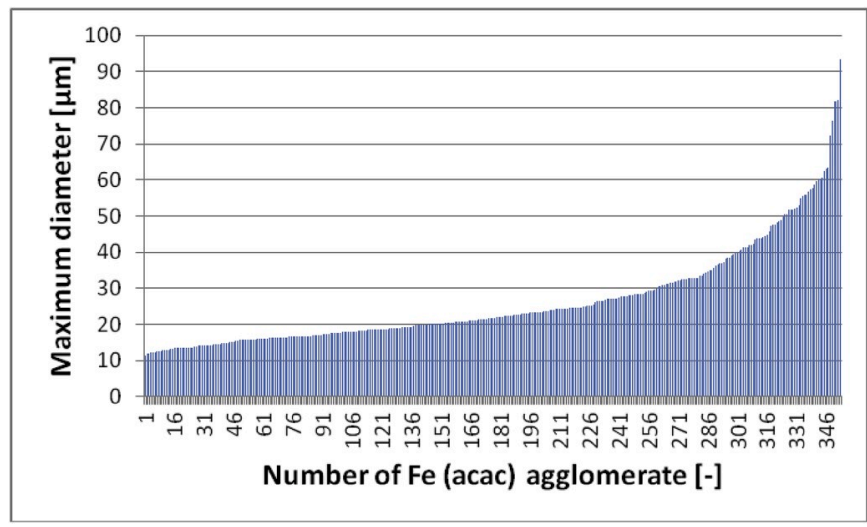

Fig. 11. Maximum diameters of Fe (acac) clusters in BIIR vulcanizates.
This can result from different activities of different possible BIIR isomeric structures [26]. The increased amount of Fe (acac) leads to the activation of less active isomeric structures and results in a second step of the vulcanization. A much smaller growth in the torque increment for the second step of the vulcanization confirms this hypothesis.

An addition of a higher content of $\mathrm{Fe}$ (acac) results in a greater reversion for the BIIR compounds. It can be an effect of higher amounts of released $\mathrm{HBr}$ during the crosslinking reaction. This causes a degradation of the polymer chain, which significantly reduces the molecular weight of BIIR (Scheme 4). The presence of a base is necessary to bond $\mathrm{HBr}$ and prevent the degradation of the polymer chain [27-32].

The absence of reversion for the sample cured with $\mathrm{Fe}$ (acac) in the presence of TEOA confirms this hypothesis. Because the alcalic TEOA bonds the acidic $\mathrm{HBr}$ produced during the vulcanization and therefore prevents the degradation of the polymer chain.

The addition of TEOA, as it was for CR, makes the Fe (acac) complex much more effective as crosslinking agent, therefore the BIIR compound containing only $0.1 \mathrm{phr}$ of $\mathrm{Fe}$ (acac) and additionally $4 \mathrm{phr}$ of TEOA yields the highest torque increment (Fig. 4).

The rubber compounds were vulcanized at the optimal vulcanization time measured during the vulcametric tests (Table 3). Because of the marching modulus character of the vulcanization curves observed for the CR compounds, the measurements for those compounds were performed for over $120 \mathrm{~min}$ to obtain a more accurate picture of the vulcanization kinetics. However, the torque value at 60th minute was used as the maximum torque to calculate $\mathrm{t} 90$ for each compound. The BIIR based compounds vulcanization kinetics measurements were performed over a shorter time period of $60 \mathrm{~min}$ because they do not show a marching modulus behavior.

Furthermore, BIIR containing only TEOA without the Fe (acac) complex also undergoes a crosslinking process (Fig. 4), which was unexpected. However, Pazur and Petrov [29] mentioned that at higher temperatures a crosslinking between adjacent chains of chlorinated or brominated isobutylene-co-isoprenepolymers through an oxidative 
<smiles>[X]C(CC(C)C)C(=C)CC(C)(CC)C(CC)(C(C)C)C(C)CC(C)(C)C</smiles><smiles>[X]CC(=CCC(C)(C)C(CC)(CC)C(C)CC(C)(C)C)CC(C)(C)C</smiles>

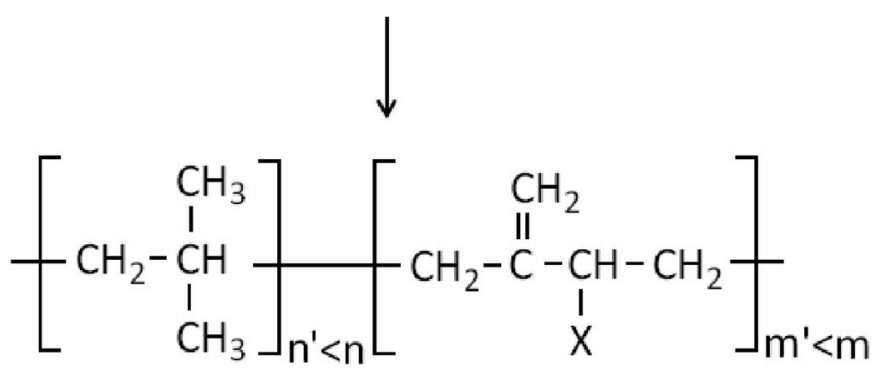

Scheme 4. Reaction of polymer chain scission in the presence of $\mathrm{HBr}$ [32].

Table 3

Optimal vulcanization time for CR or BIIR - based compounds at $160{ }^{\circ} \mathrm{C}$, t90-optimal vulcanization time.

\begin{tabular}{|c|c|c|c|}
\hline \multicolumn{2}{|c|}{$<!-$ Col Count:5- > CR - based compounds } & \multicolumn{2}{|l|}{ BIIR - based compounds } \\
\hline Compound description & $\mathrm{t}_{90}[\mathrm{~min}]$ & Compound description & $\mathrm{t}_{90}[\mathrm{~min}]$ \\
\hline CR & 48 & BIIR & - \\
\hline $\mathrm{CR}, 0.05 \mathrm{Fe}$ & 39 & BIIR, $0.05 \mathrm{Fe}$ & 17 \\
\hline $\mathrm{CR}, 0.1 \mathrm{Fe}$ & 38 & BIIR, $0.1 \mathrm{Fe}$ & 16 \\
\hline $\mathrm{CR}, 0.2 \mathrm{Fe}$ & 34 & BIIR, $0.2 \mathrm{Fe}$ & 11 \\
\hline $\mathrm{CR}, 0.3 \mathrm{Fe}$ & 23 & BIIR, $0.3 \mathrm{Fe}$ & 11 \\
\hline $\mathrm{CR}, 0.4 \mathrm{Fe}$ & 12 & BIIR, $0.4 \mathrm{Fe}$ & 11 \\
\hline $\mathrm{CR}, 0.5 \mathrm{Fe}$ & 24 & BIIR, $0.5 \mathrm{Fe}$ & 14 \\
\hline $\mathrm{CR}, 0.6 \mathrm{Fe}$ & 15 & BIIR, 0.6 Fe & 19 \\
\hline CR, $0.7 \mathrm{Fe}$ & 9 & BIIR, $0.7 \mathrm{Fe}$ & 21 \\
\hline $\mathrm{CR}, 0.8 \mathrm{Fe}$ & 9 & BIIR, $0.8 \mathrm{Fe}$ & 22 \\
\hline $\mathrm{CR}, 0.9 \mathrm{Fe}$ & 4 & BIIR, $0.9 \mathrm{Fe}$ & 24 \\
\hline $\mathrm{CR}, 1.0 \mathrm{Fe}$ & 4 & BIIR, $1.0 \mathrm{Fe}$ & 24 \\
\hline CR, $0.1 \mathrm{Fe}, 4 \mathrm{TEOA}$ & 9 & BIIR, $0.1 \mathrm{Fe}, 4 \mathrm{TEOA}$ & 15 \\
\hline CR, 4TEOA & 26 & BIIR, 4TEOA & 35 \\
\hline
\end{tabular}

induced elimination of the halogenated acid can take place (Scheme 5).

According to this, for higher temperatures it is assumed that crosslinking recombination reactions are in competition with chain breaking reactions. It could explain not only the absence of the reversion for the sample with Fe (acac) in the presence of TEOA, but also the increase of the torque for the sample containing only TEOA.

\subsection{The degree of crosslinking of $C R$ and BIIR vulcanizates}

A comparison of the degree of crosslinking and torque increment for CR vulcanizates and BIIR vulcanizates are presented in Fig. 12 and Fig. 13 respectively. The values of the crosslinking degree determined by equilibrium swelling correlates very well with the torque increment because in unfilled rubber compounds only the crosslink density is responsible for a torque increment during rheometrical test. As shown, $\mathrm{Fe}$ (acac) is more efficient as a new curing agent for CR than for BIIR compounds. It is a result of the thermal curing ability of $\mathrm{CR}$ and much higher halogenation level and double bonds content in CR comparing to BIIR. Moreover, for the same reason, it was necessary to use a greater amount of $\mathrm{Fe}$ (acac) (minimum $0.4 \mathrm{phr}$ ) for BIIR to prepare vulcanizates, which contain a sufficient crosslinking degree. The results for BIIR vulcanizates containing $0.4 \mathrm{phr}$ or more of $\mathrm{Fe}$ (acac) are presented in Fig. 13. Similarly to the rheometrical studies, an increase of the crosslinking degree with rising amount of $\mathrm{Fe}$ (acac) from 0.05 to $0.7 \mathrm{phr}$ for $\mathrm{CR}$ and from 0.4 to $0.9 \mathrm{phr}$ for BIIR is observed. Moreover, a much higher activity of $\mathrm{Fe}$ (acac) in the presence of TEOA and consequently a higher degree of crosslinking was achieved for both rubbers. Therefore, these measurements confirm the crucial effect of TEOA presence on the kinetic of vulcanization and the degree of crosslinking. This indicates that the crosslinking process follows the mechanism of the Heck reaction.

\subsection{DSC studies}

A DSC analysis was applied to investigate the activity of Fe (acac) and the influence of TEOA on the temperature and enthalpy of the CR and BIIR vulcanization (Fig. 14 and Fig. 15 respectively). In order to investigate the contribution of the CR thermal curing, the pristine rubber without addition of a crosslinking system was also studied. According to rheometrical tests, BIIR compounds did not exhibit thermal curing, therefore, the pristine rubber without addition of a crosslinking system was not studied. In general, in the DSC curves the following effects were observed: 1. A slope from the glass transition temperature (at approx. $-40{ }^{\circ} \mathrm{C}$ ) that indicates the conversion from the rigid glass-state into the visco-elastic state as a result of a rapid increase of macromolecules segmental mobility; 2. Afterwards, a peak corresponding to the melting of the crystalline phase (at approx. $40^{\circ} \mathrm{C}$ ), which is comprised of regular trans-1,4 units; 3 . Finally exothermic peaks from the vulcanization start at $103-134{ }^{\circ} \mathrm{C}$ and disappear at $172-244^{\circ} \mathrm{C}$ depending on the sample.

Semicrystalline and amorphous materials reveal a glass transition after cooling to a sufficiently low temperature. Above the glass transition, the material is a more or less viscous liquid. The molecules can perform liquid-specific cooperative rearrangements. Below the glass transition temperature, cooperative molecular rearrangements are 'frozen'. The material is in a glassy state and the change in molecular mobility causes a step in the heat capacity curve. The shape of the curve at the glass transition varies depending on the thermal and mechanical history of the sample [34].

According to the crystallization rate and applications, CR is classified into four types. The M type, which was used, has a medium crystallization rate. Because of the tendency of CR to crystalize bigger peaks from the melting of this crystallization phase are observed compared to

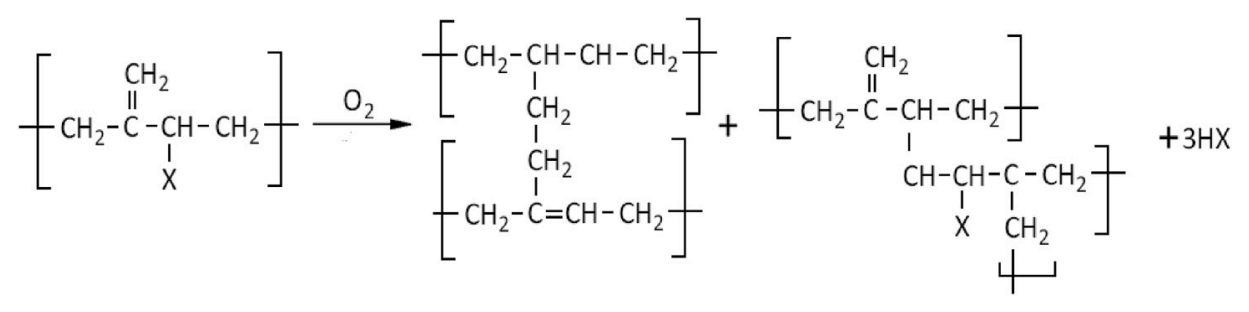

Scheme 5. Crosslinking between adjacent chains of halogenated butyl rubber based on [33]. 


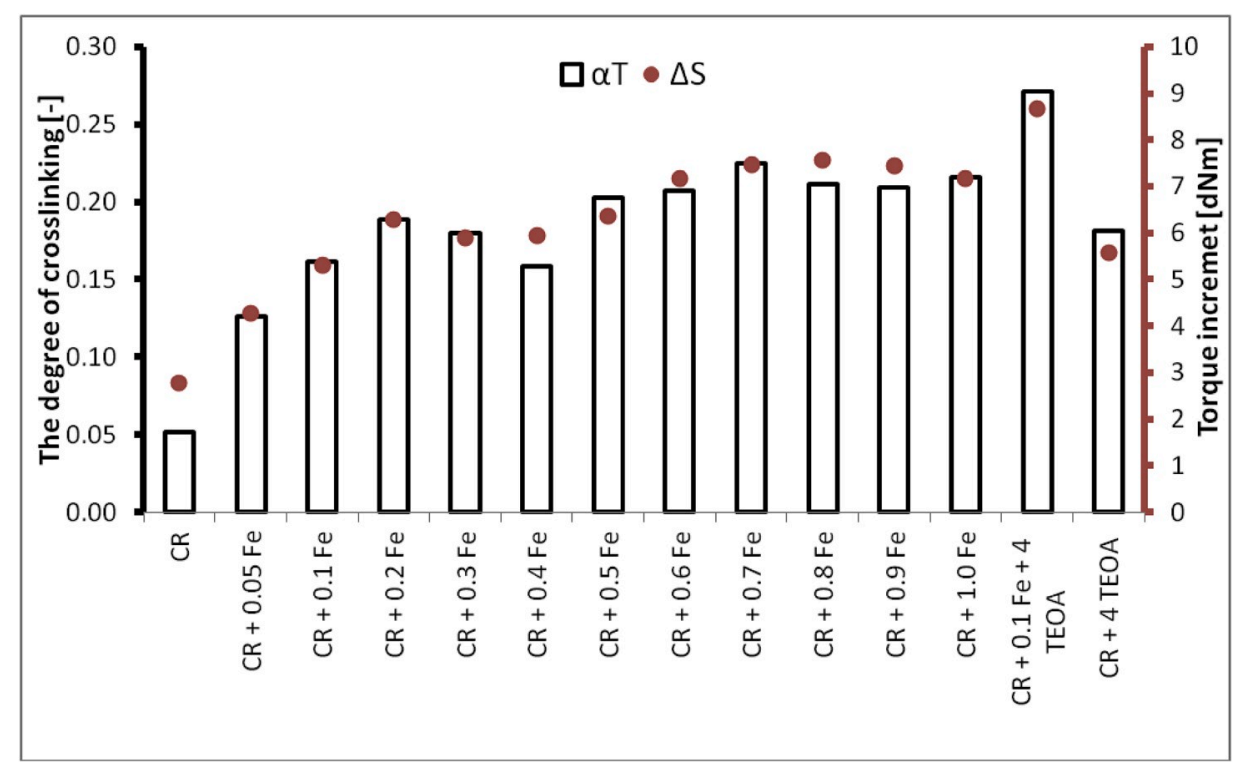

Fig. 12. Comparison of the degree of crosslinking and torque increment for CR vulcanizates.

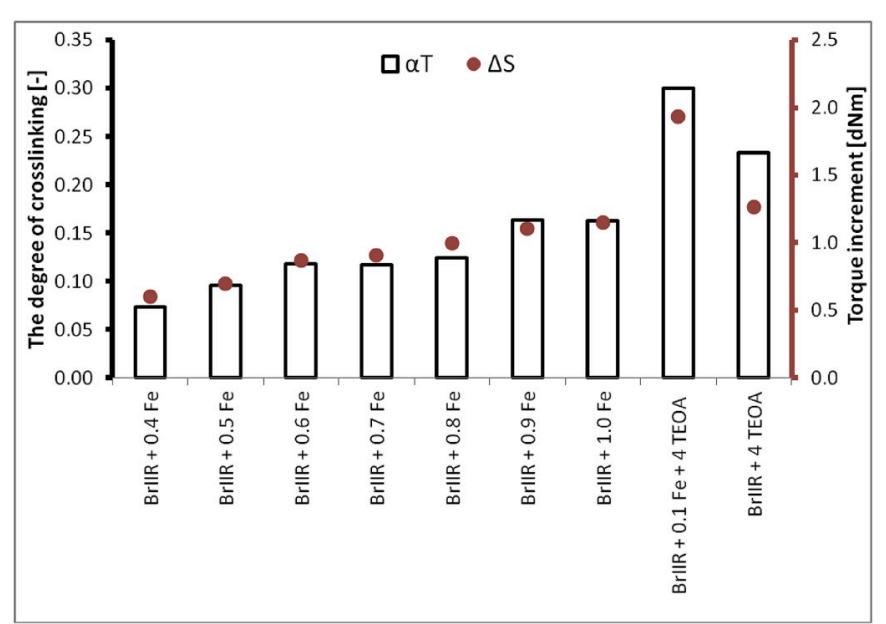

Fig. 13. Comparison of the degree of crosslinking and torque increment for BIIR vulcanizates.

BIIR compounds. It is worth noting that the melting behavior of the crystallization phase depends not only on the chemical structure of the sample, but also on its thermal and mechanical history [35].

Moreover, the height of the glass transition step also depends on the crystallinity. If the degree of the crystallinity is greater, $\Delta C_{p}$ is smaller because the proportion of the mobile amorphous material involved in the glass transition is lower. It is especially evident when the $\Delta C_{p}$ for CR and BIIR is compared (Figs. 14 and 15). For BIIR compounds, which has a much lower crystallization phase, a much higher glass transition step is consequently observed. The crystallinity also influences the glass transition temperature. The glass transition temperature of the sample with a larger degree of crystallinity is significantly higher. This is a result of the decrease of the molecular mobility in the amorphous regions due to the crystallites [35].

However, to investigate the mechanism of the vulcanization reaction, the exothermic peaks are the most important part of the DSC curves. In Figs. 14 and 15, the DSC results for CR and BIIR compounds are presented. To investigate the influence of the base TEOA on the curing activity of the catalyst, rubber compounds containing only the catalyst and the catalyst in the presence of TEOA, were prepared. Additionally, the thermal curing of CR was observed in Fig. 14.
The results presented confirm that $\mathrm{CR}$ can be cured thermally without the incorporation of a crosslinking agent $(2.9 \mathrm{~J} / \mathrm{g})$, as it was noticed during the rheometer test. The enthalpy of this process and the vulcanization enthalpy of $\mathrm{CR}$ with $0.1 \mathrm{Fe}$ (acac) $(1.8 \mathrm{~J} / \mathrm{g}$ ) is definitely lower in comparison to $\mathrm{CR}$ cured with $0.1 \mathrm{phr}$ of $\mathrm{Fe}$ (acac) in the presence of $4 \mathrm{phr}$ TEOA $(35.6 \mathrm{~J} / \mathrm{g})$. A similar effect is observed for the enthalpy of the BIIR compounds vulcanization (Fig. 15). An addition of TEOA to BIIR compounds results in a greater enthalpy of the vulcanization $(9.7 \mathrm{~J} / \mathrm{g})$ in comparison to a compound with Fe (acac) alone (6.7 $\mathrm{J} / \mathrm{g}$ ). This shows the influence of TEOA on the crosslinking process, proving that its nature is based on the Heck-type reaction mechanism.

\subsection{Inactivity of the curing system in non-halogenated rubber and acid environment}

A Heck-type reaction requires the presence of halogenation in the structure of one substrate together with a basic environment (Scheme 1). To confirm the correctness of the hypothesis about the assumed mechanism of the crosslinking reaction, a non-halogenated butyl rubber (IIR) was tested in comparison to BIIR. BIIR was chosen instead of the more reactive $C R$ due to the fact that BIIR cannot be crosslinked without the addition of a curative in contrary to CR. Different IIR - based compounds, which contained $0.1 \mathrm{phr}$ of $\mathrm{Fe}$ (acac), $0.1 \mathrm{phr}$ of $\mathrm{Fe}$ (acac) in the presence of $4 \mathrm{phr}$ of TEOA or $4 \mathrm{phr}$ of TEOA alone were prepared in order to compare the kinetic behavior of the vulcanization with their halogenated analogue (BIIR). All compounds were prepared according to the same mixing procedure as the previous rubber blends (Table 2). After the rubber compound preparation, the curing behavior was studied (Fig. 16). The results presented in Fig. 16 demonstrate the inactivity of the new curing agents for all prepared IIR compounds and confirmed the assumption about the Heck-type mechanism of BIIR crosslinking.

For the further analysis, the environment of the BIIR vulcanization reaction was acidified by stearic acid addition instead of TEOA. The compounds were prepared according to the same mixing procedure as used in the previously described rubber blends. The curing behavior of pure BIIR and of BIIR with $0.1 \mathrm{phr}$ of Fe (acac) in the presence of $4 \mathrm{phr}$ of stearic acid or TEOA are presented in Fig. 17.

As shown in Fig. 17, an application of Fe (acac) in the acidic environment of stearic acid did not result in a crosslinking of BIIR, whereas in the presence of TEOA a significant torque increase is observed during the vulcanization. This confirms that the mechanism of crosslinking is based on the Heck reaction, which means that a transition metal 


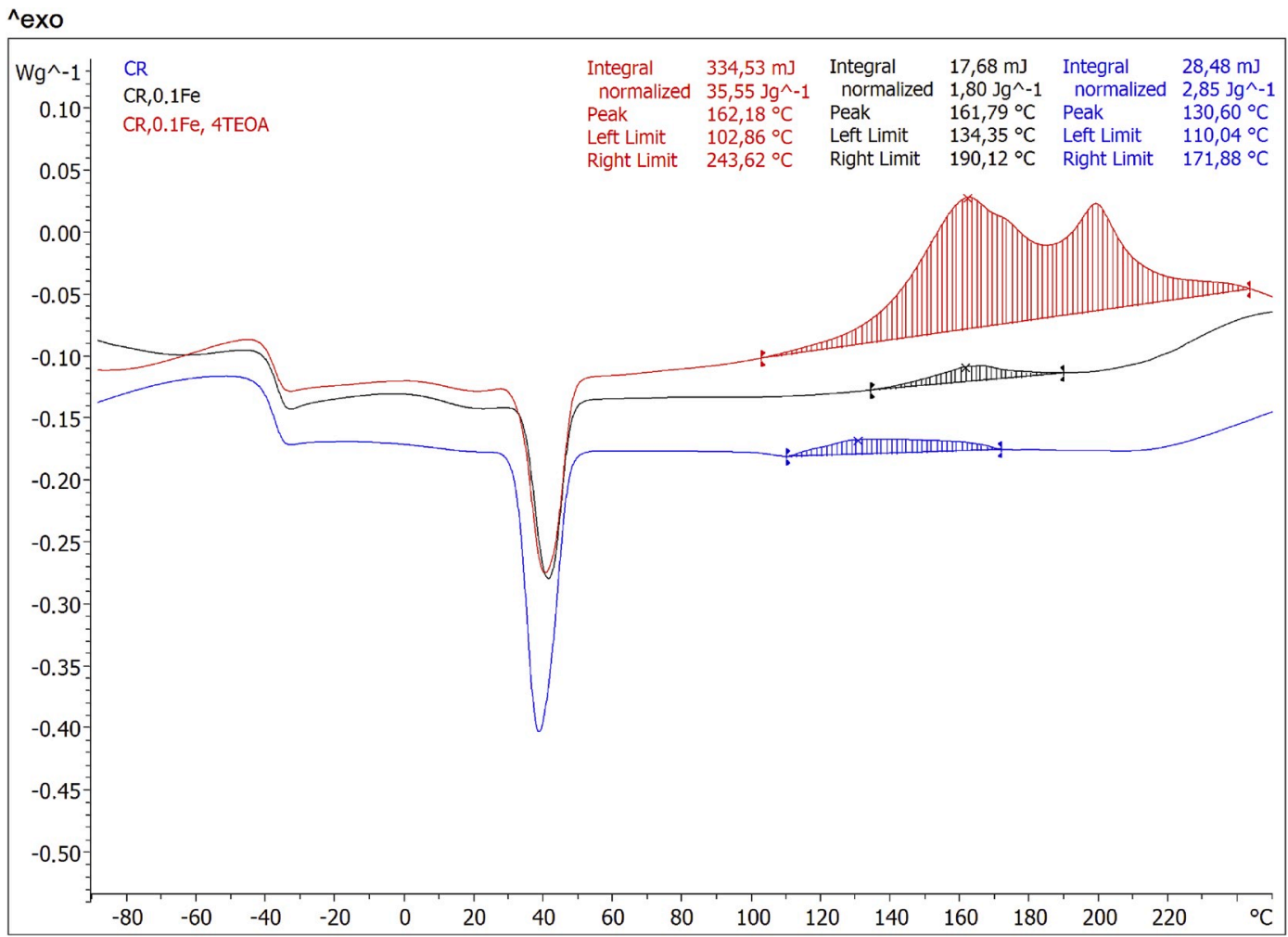

Fig. 14. DSC curves for CR compounds.

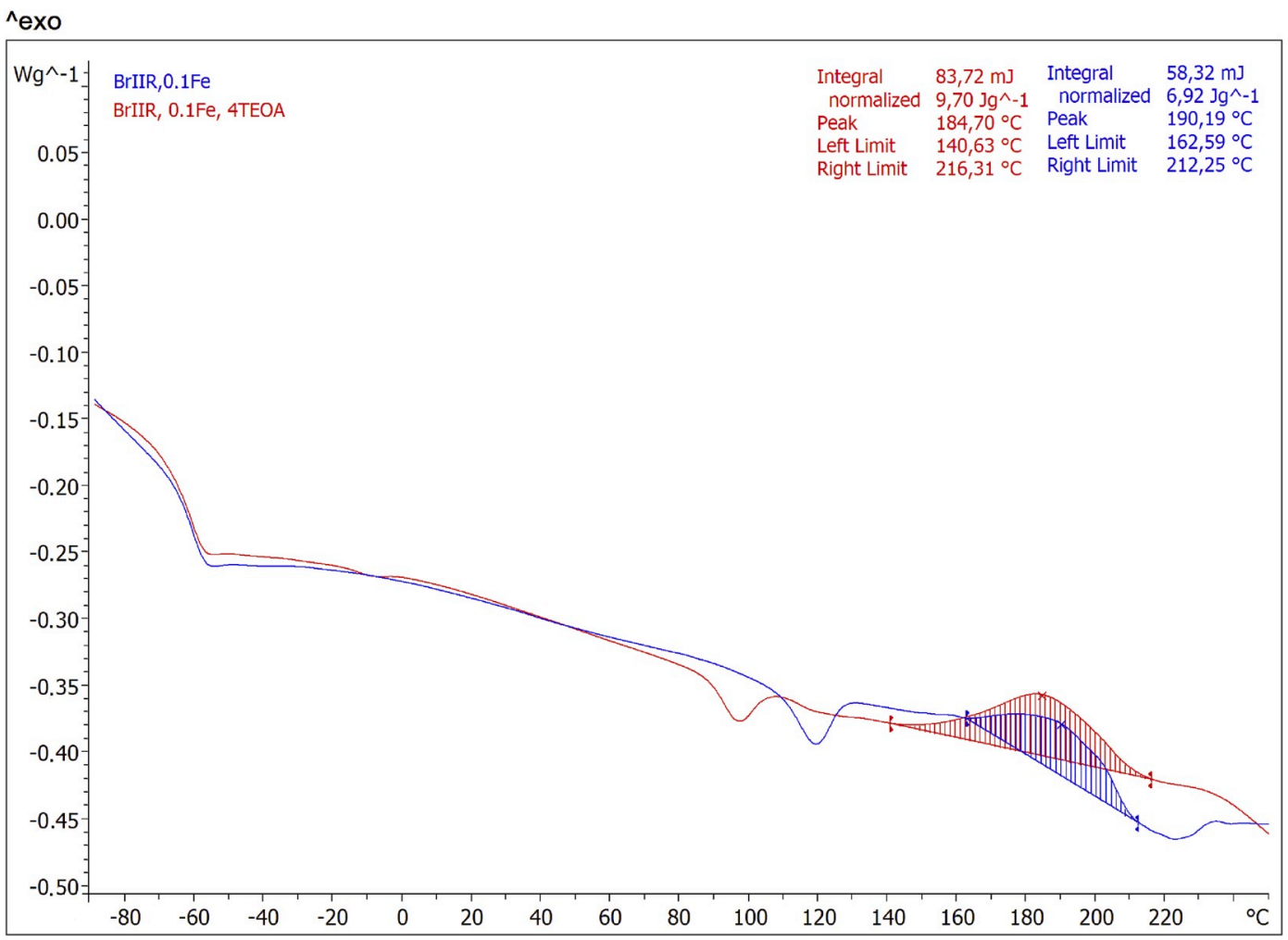

Fig. 15. DSC curves for BIIR compounds.

complex and a basic environment are required to achieve a high efficiency of the crosslinking.

\subsection{FTIR studies}

FTIR studies were performed to evaluate changes in the chemical structure of rubber after the vulcanization process. Additionally, FTIR 


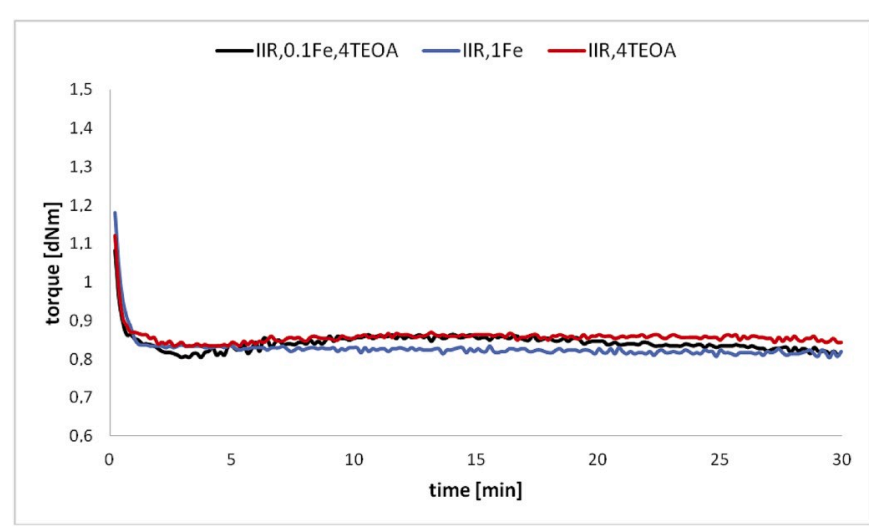

Fig. 16. The vulcanization kinetics of the IIR compound. spectrum of pure iron acetylacetonate was presented as a standard in Fig. 18. The analysis of FTIR spectra of all uncured and cured CR compounds demonstrates the presence of a small band in a range of 1770 $\mathrm{cm}^{-1}$. This band corresponds to a halogen atom directly connected to a carbonyl group, which is present in the Fe (acac) structure (Scheme 3). Such intermediate structure is expected to appear during a Heck reaction in the absence of a base.

In Fig. 19 FTIR spectras for cured and uncured CR that contain 0.5 phr of $\mathrm{Fe}$ (acac) are presented. The presence of the reaction intermediates in which $\mathrm{Fe}$ (acac) is connected to halogen atom results in the appearance of a small band at $1770 \mathrm{~cm}^{-1}$ only for the cured rubber. This interaction is present only in the absence of TEOA, which would bond the acid after the intermediate Fe (acac)/acid interaction. Fig. 20 was prepared to highlight the changes of intensity of the band in relation to the amount of the Fe (acac) complex. This band was observed only for the cured compounds in the presence of $\mathrm{Fe}$ (acac). No signal was recorded for the uncured compounds and for the compounds that contained TEOA. The results shown in Fig. 20 indicate that a smaller quantity of $\mathrm{Fe}$ (acac) results in a lower $1770 \mathrm{~cm}^{-1}$ band intensity

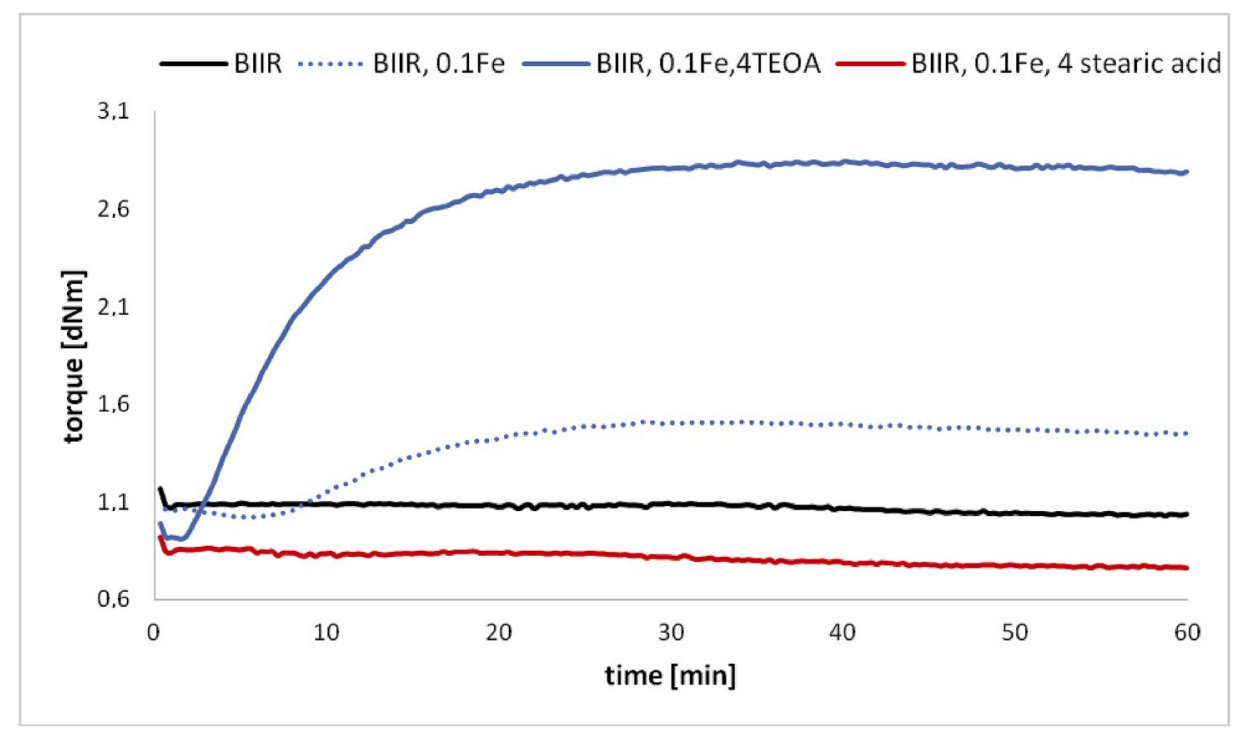

Fig. 17. The vulcanization kinetics of the BIIR compound with Fe (acac) in an acidic environment.

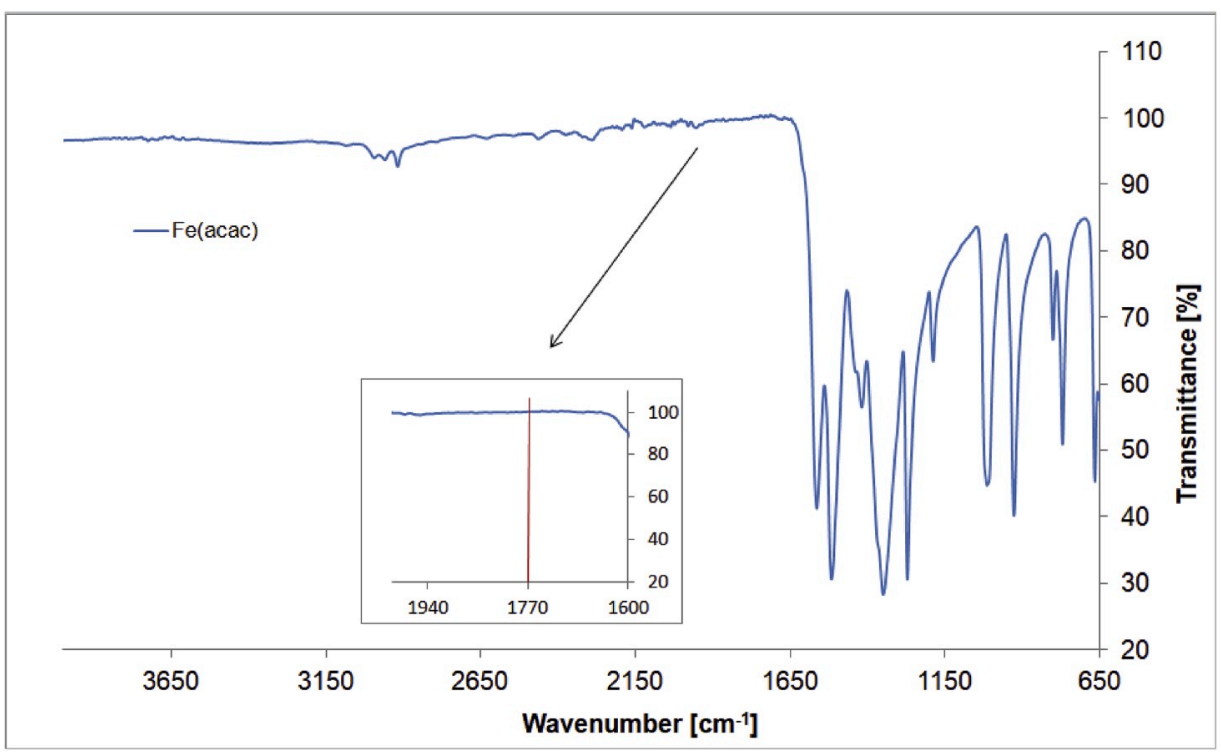

Fig. 18. FTIR spectrum for pure Fe (acac). 


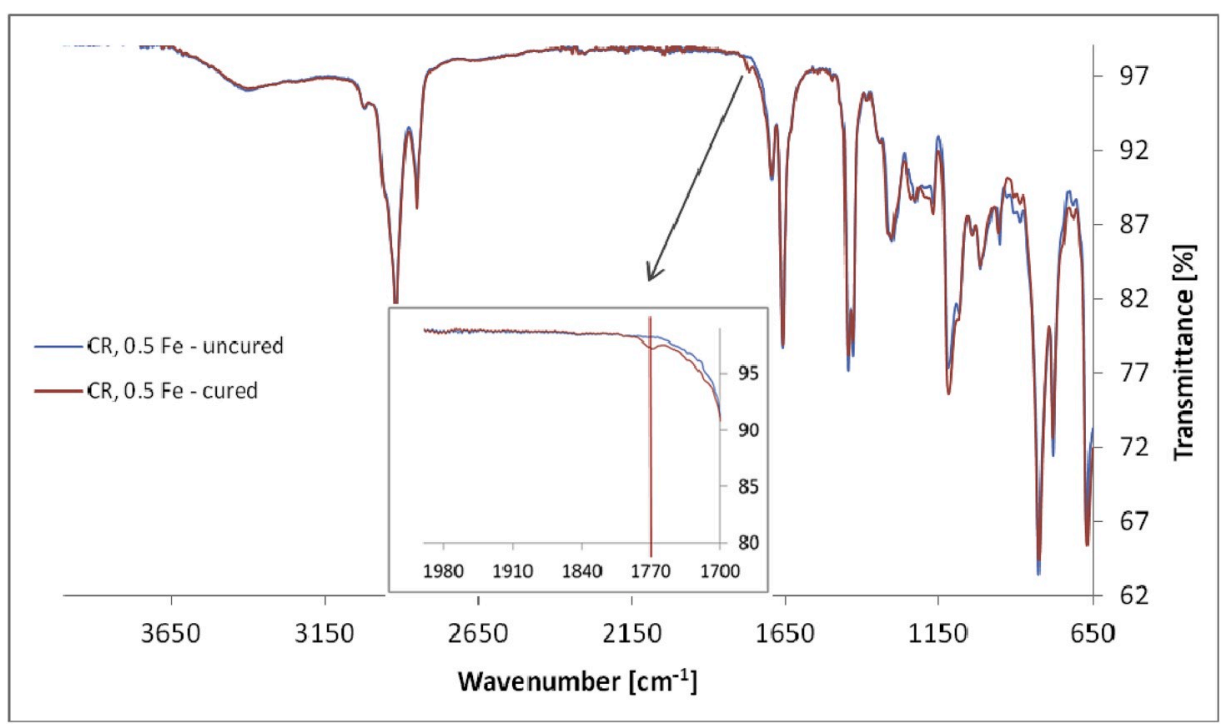

Fig. 19. FTIR spectrum for uncured and cured CR with $0.5 \mathrm{phr}$ of Fe (acac).

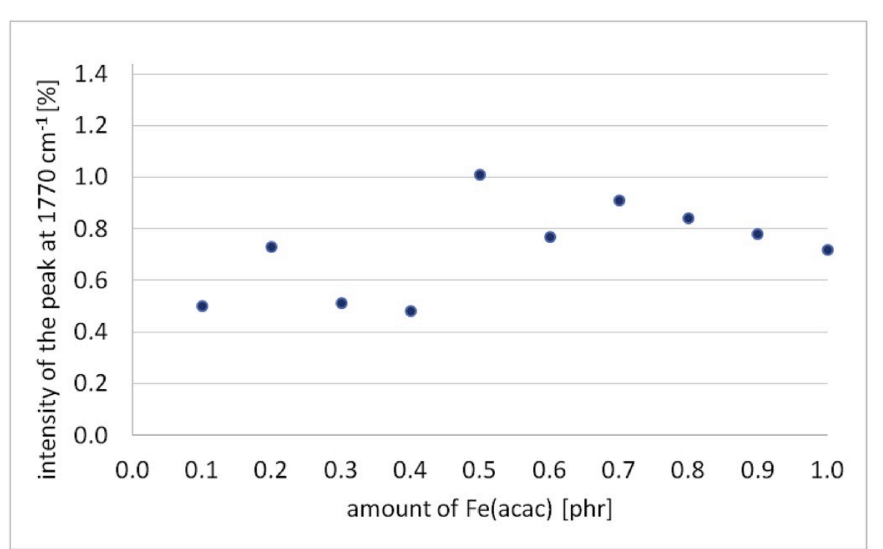

Fig. 20. The intensity of the band at $1770 \mathrm{~cm}^{-1}$ for FTIR spectras of cured samples containing Fe (acac). whereas higher amounts leads to more intensive peaks. The increase in the intensity of the band at $1770 \mathrm{~cm}^{-1}$ is not growing precisely in accordance to the amount of incorporated Fe (acac). This is most likely related to the probably insufficient dispersion of the metal complex in the rubber matrix as it was shown in the case of the torque increment.

According to the mechanism proposed by Yao et al. (Scheme 2) it can be concluded that during the vulcanization process, the formation of species containing halogen connected close to a carbonyl group from the catalyst ligand takes place (structure II or III in Scheme 2). Afterwards the regeneration of active catalyst occurs in the presence of a base [15, 17]. According to this knowledge, a band at $1770 \mathrm{~m}^{-1}$ appears only for the rubber compounds cured with Fe (acac) without TEOA. For the uncured compounds or the compounds cured in the presence of the TEOA base this band is not observed. This is confirmed by the FTIR measurements presented in Figs. 21-23.

Fig. 21 presents FTIR spectra of uncured and thermally cured CR without any additives. No band at $1770 \mathrm{~cm}^{-1}$ was observed for both samples, which confirms the proposed thesis.

As mentioned, during the Heck-type reaction, the metal complex is connected to halogen but the addition of TEOA leads to a release of this halogen [15]. Therefore, concerning a Heck-type reaction, the band at $1770 \mathrm{~cm}^{-1}$ should occur only for the vulcanizates crosslinked with $\mathrm{Fe}$

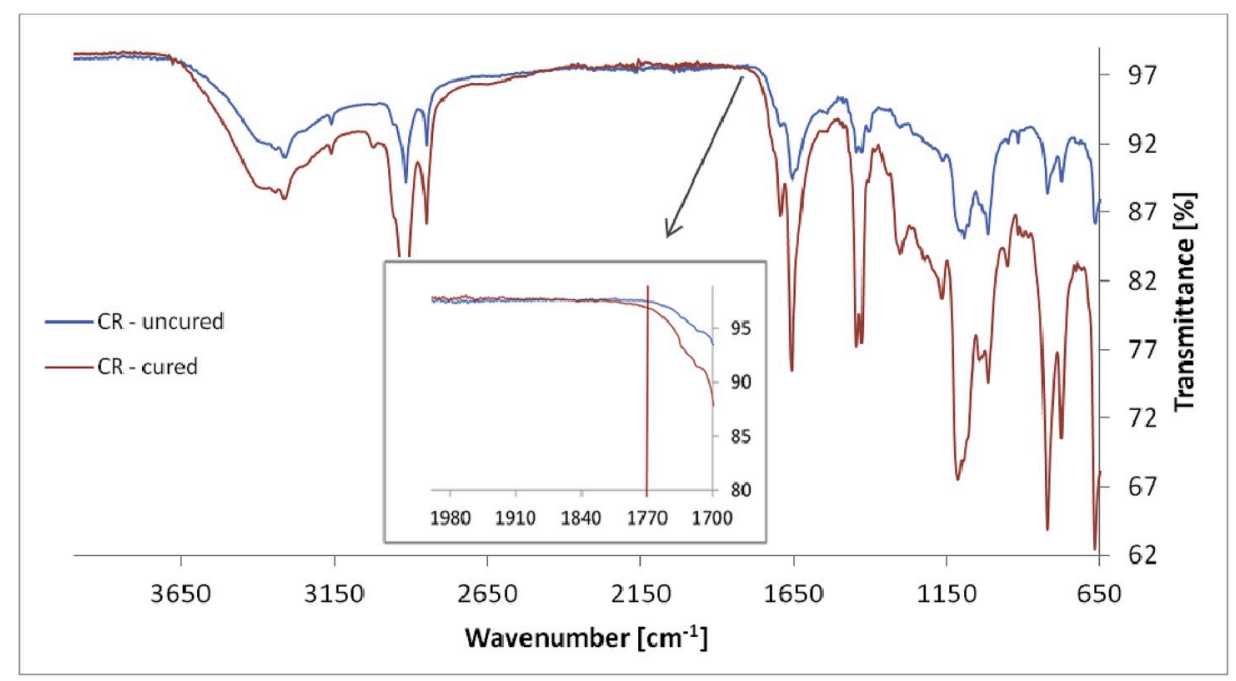

Fig. 21. FTIR spectrum for cured and uncured CR without Fe (acac) and TEOA. 


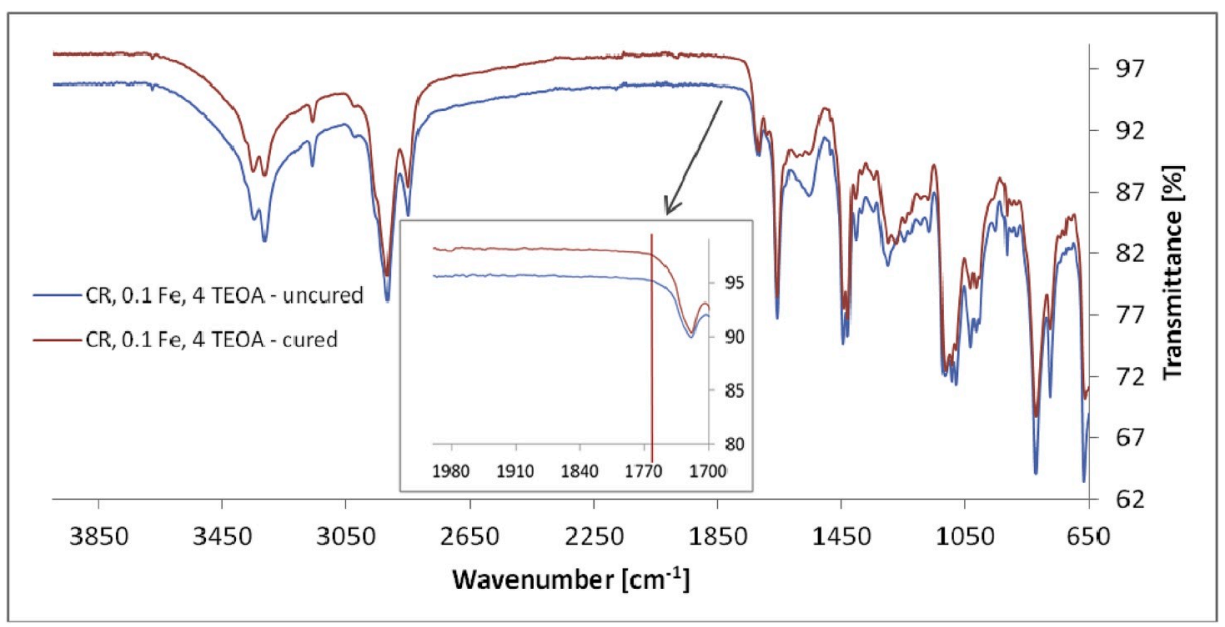

Fig. 22. FTIR spectrum for cured and uncured CR samples with $0.1 \mathrm{phr}$ of Fe (acac) in the presence of TEOA.

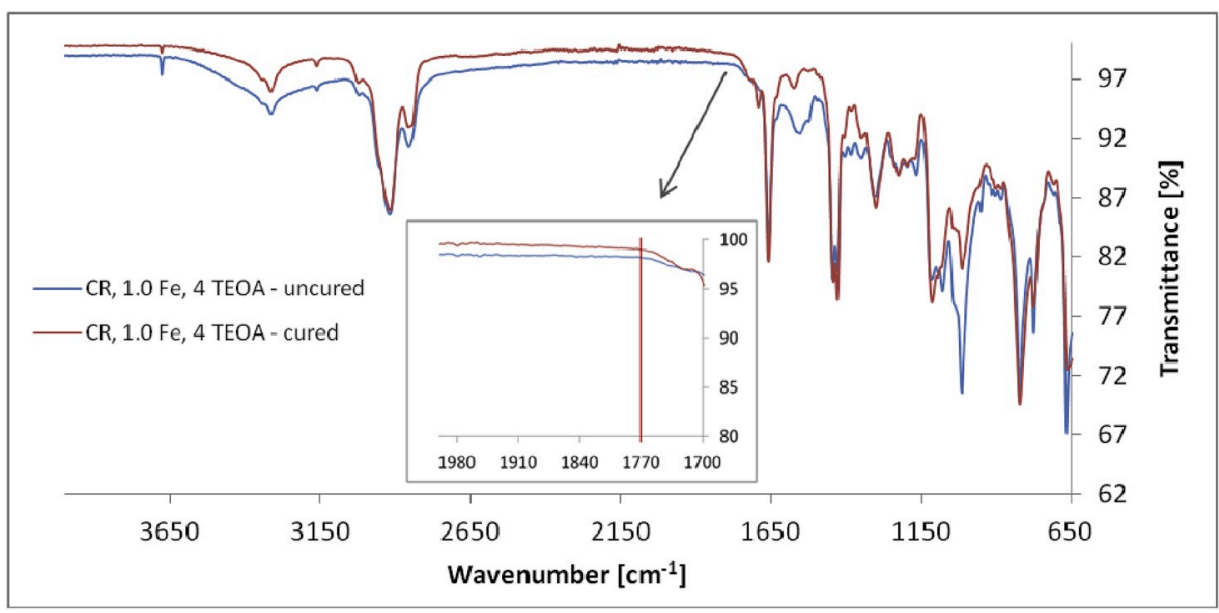

Fig. 23. FTIR spectrum for cured and uncured CR sample with 1 phr of Fe (acac) and 4 phr of TEOA.

(acac) and should disappear when TEOA is added. The absence of this band for the sample contained $0.1 \mathrm{phr}$ of $\mathrm{Fe}$ (acac) and $4 \mathrm{phr}$ of TEOA was confirmed by FTIR spectrum presented in Fig. 22.

To have an evidence that the absence of the band at $1770 \mathrm{~cm}^{-1}$ for a CR compound containing TEOA does not result from an insufficient amount of $\mathrm{Fe}$ (acac), an additional sample containing $1 \mathrm{phr}$ of Fe (acac) and $4 \mathrm{phr}$ of TEOA was prepared (accordingly to previously described procedure) and studied. FTIR spectrum of this uncured and cured rubber compound is presented in Fig. 23. No band at $1770 \mathrm{~cm}^{-1}$ was observed for both uncured and cured compound, which strongly confirms the hypothesis about the Heck-type mechanism of crosslinking.

\section{Conclusions}

The kinetics of vulcanization and the degree of crosslinking of the $\mathrm{CR}$ and BIIR compounds confirmed the high activity of $\mathrm{Fe}$ (acac) as a curing agent for halogenated diene rubber. A much higher torque increment and the higher degree of crosslinking of the compounds containing $\mathrm{Fe}$ (acac) and TEOA confirmed that the application of TEOA increases the efficiency of the proposed crosslinking system due to its alkaline character. Moreover, the enthalpy of the vulcanization was much higher for $\mathrm{CR}$ containing Fe (acac)/TEOA system. The compounds that contained $\mathrm{Fe}$ (acac) in the presence of TEOA exhibit the highest degree of crosslinking even when they are compared to the compounds that contained 10 folds more of $\mathrm{Fe}$ (acac). It indicates the high importance of TEOA in the reaction and confirms the assumptions about the Heck type crosslinking mechanism.

Moreover, the applied curing agent is inactive when the rubber chains do not contain a halogen atom, or the environment of the reaction is not basic. This finding confirms that the crosslinking process of the halogenated diene rubber studied follows the mechanism of Heck-type reaction.

The strongest evidence, which confirms the proposed mechanism of crosslinking results from the FTIR studies. An analysis of FTIR spectra of all uncured and cured samples demonstrated a presence of a small band at $1770 \mathrm{~cm}^{-1}$ only for rubber compounds cured only in the presence of Fe (acac). This band corresponds to a halogen which is directly connected to a carbonyl group. According to the Heck reaction mechanism proposed by Yao et al. (Scheme 2) this band should occur only for the vulcanizates crosslinked with Fe (acac) and should not be observed when TEOA is used. All analyzed FTIR spectras certified this proposed thesis.

The confirmed mechanism offers new possibilities to improve the crosslinking process of halogenated rubbers. Despite the undeniable advantages: high activity achieved with a very small amount of curing system; relatively low price and elimination of $\mathrm{ZnO}$ from the recipe, a very low scorch time observed for the composites with Fe (acac) is the biggest disadvantage from the point of view of safe rubber processability. It impedes the application of this curing system in the industry and must be improved. The first approach to delay the reaction of 
crosslinking may be implementation an acidic environment at the beginning of the reaction with simultaneous addition of a compound exhibiting alkaline properties activated in time. Another method may be application of different basis used typically in Heck reaction with a higher activity for BIIR and lower activity for CR but also simpler method as decrease temperature of the crosslinking.

\section{Funding}

This work was supported by the Young Scientists' Fund at the Faculty of Chemistry, Lodz University of Technology [Grant W-3D/FMN/34G/ 2016].

\section{Data availability}

The raw/processed data required to reproduce these findings cannot be shared at this time due to technical or time limitations.

\section{Declaration of competing interest}

The authors declare that they have no known competing financial interests or personal relationships that could have appeared to influence the work reported in this paper.

\section{CRediT authorship contribution statement}

Anna Dziemidkiewicz: Conceptualization, Methodology, Investigation, Writing - original draft, Visualization, Funding acquisition. Rafał Anyszka: Conceptualization, Methodology, Resources, Writing - review \& editing, Visualization, Supervision. Anke Blume: Resources, Writing review \& editing, Supervision, Funding acquisition. Magdalena Maciejewska: Resources, Writing - review \& editing, Visualization.

\section{Acknowledgments}

The authors acknowledge the KEYENCE INTERNATIONAL (Bielany Wrocławskie, Poland) for Laser Scanning Confocal Microscope images of $\mathrm{CR}$ or BIIR vulcanizates.

\section{References}

[1] T. Mizoroki, K. Mori, A. Ozaki, Arylation of olefin with aryl iodide catalyzed by palladium, Bull. Chem. Soc. Jpn. 44 (1971) 581.

[2] R.F. Heck, J.P. Nolley, Palladium-catalyzed vinylic hydrogen substitution reactions with aryl, benzyl, and styryl halides, J. Org. Chem. 37 (1972) 2320-2322.

[3] S. Jagtap, Heck reaction - state of the art, Catalysts 7 (2017) 267-320.

[4] A. Jutand, Mechanisms of the mizoroki-heck reaction, in: M. Oestreich (Ed.), The Mizoroki-Heck Reaction, first ed., John Wiley \& Sons, Chichester, 2009, pp. 1-50.

[5] S.B. Waghmode, S.S. Arbuj, B.N. Wani, C.S. Gopinath, Palladium chloride catalyzed photochemical Heck reaction, Can. J. Chem. 91 (2013) 348-351.

[6] W. Cabri, I. Candiani, Recent developments and new perspectives in the Heck reaction, Acc. Chem. Res. 28 (1995) 2-7.

[7] B.M. Bhanage, S. Fujita, M. Arai, Heck reactions with various types of palladium complex catalysts: application of multiphase catalysis and supercritical carbon dioxide, J. Organomet. Chem. 687 (2003) 211-218.

[8] K. Gholivand, R. Salami, K. Farshadfar, R.J. Butcher, Synthesis and structural characterization of $\mathrm{Pd}(\mathrm{II})$ and $\mathrm{Cu}(\mathrm{I})$ complexes containing dithiophosphorus ligand and their catalytic activities for Heck reaction, Polyhedron 119 (2016) 267-276.
[9] S.Z. Tasker, A.C. Gutierrez, T.F. Jamison, Nickel-catalyzed mizoroki-heck reaction of aryl sulfonates and chlorides with electronically unbiased terminal olefins: high selectivity for branched products, Angew. Chem. Int. Ed. 53 (2014) 1858-1861.

[10] T.M. Bulatov, M.V. Pugachev, N.V. Shtyrlin, Y.G. Shtyrlin, Novel approach to 6alkenyl;-substituted derivatives based on the Heck reaction, Tetrahedron let 59 (2018) 3220-3222.

[11] J.B. Sweeney, K. Adams, J. Doulcet, B. Thapa, F. Tran, R. Crook, Optimizing the Mizoroki-Heck reaction of cyclic allyl amines: gram-scale synthesis of preclamol without protecting groups, J. Catal. 360 (2018) 97-101.

[12] F. Zhao, L. Xin, Y. Zhang, X. Jia, Monodentate phosphorus-coordinated palladium (II) complexes as new catalyst for Mizoroki-Heck reaction of aryl halides with electron-deficient olefins, Chin. Chem. Lett. 29 (2018) 493-496.

[13] J. Wang, B. Mu, Z. Fu, L. Wang, T. Li, Y. Wu, Cyclopalladated ferrocenylimines with ester groups for Heck and Suzuki coupling reactions, Chin. J. Catal. 35 (2014) 1059-1067.

[14] R.F. Heck, New applications of palladium in organic syntheses, Pure Appl. Chem. 50 (1978) 691-701.

[15] S. Wang, G. Yang, Recent developments in low-cost TM-catalyzed Heck-type reactions (TM=transition metal, Ni, Co, Cu, Fe), Catal. Sci. Technol. 6 (2016) 2862-2876.

[16] J.G. de Vries, The Heck reaction in the production of fine chemicals, Can. J. Chem. 79 (2001) 1086-1092.

[17] Q. Yao, E.P. Kinney, Z. Yang, Ligand-free Heck reaction: $\mathrm{Pd}(\mathrm{OAc})_{2}$ as an active catalyst revisited, J. Org. Chem. 68 (2003) 7528-7531.

[18] A. Dziemidkiewicz, M. Pingot, K. Strzelec, M. Zaborski, Unconventional crosslinking method of polychloroprene, in: 6th International Seminar on Modern Polymeric Materials for Environmental Applications, 2016.

[19] M. Pingot, M. Zaborski, K. Strzelec, N. Sienkiewicz, Method for Crosslinking of Chloroprene Rubber, Polish Pat, 2014. PL 226286 B1.

[20] A. Dziemidkiewicz, M. Pingot, M. Maciejewska, Metal complexes as new proecological crosslinking agents for chloroprene rubber based on Heck coupling reaction, Rubber Chem. Technol. 92 (2019) 589-597, https://doi.org/10.5254/ rct.19.81465.

[21] A. Dziemidkiewicz, M. Maciejewska, M. Pingot, Thermal Analysis of Halogenated Rubber Cured with a New Crosslinking System, 2019, https://doi.org/10.1007/ s10973-019-08881-7.

[22] A. Dziemidkiewicz, M. Maciejewska, Novel environmentally friendly curing system for brominated butyl rubber, in: $7^{\text {th }}$ International Seminar on Modern Polymeric Materials for Environmental Applications, 2019.

[23] R. Musch, H. Magg, Polychloroprene rubber, in: R.C. Klingender (Ed.), Handbook of Specialty Elastomers, CRC Press, Boca Raton, USA, 2008, pp. 15-17, 2008.

[24] REGULATION (EC) No 1272/2008 of the EUROPEAN PARLIAMENT and of the COUNCIL of 16 December 2008 on Classification, Labeling and Packaging of Substances and Mixtures, Amending and Repealing Directives 67/548/EEC and 1999/45/EC, and Amending Regulation (EC) No 1907/2006.

[25] K.I. Berry, The Quest for a Safer Accelerator for Polychloroprene Rubber. PhD Thesis, Aston University Dec. United Kingdom, 2013.

[26] I.J. Gardner, J.V. Fusco, N.F. Newman, R.C. Kowalski, W.M. Davis, F.P. Baldwin, Halogenated butyl rubber, US Pat 4 (2010), 703,091.

[27] P. Xie, K. Wang, G. Luo, Calcium stearate as an acid scavenger for synthesizing high concentrations of bromobutyl rubber in a microreactor system, Ind. Eng. Chem. Res. 57 (2018) 3898-3907.

[28] P. Xie, K. Wang, P. Wang, Y. Xia, G. Luo, Synthesizing bromobutyl rubber by a microreactor system, AIChE J. 63 (2017) 1002-1009.

[29] P.J. Pazur, I. Petrov, The thermo-oxidation of chlorinated and brominated isobutylene-co-isoprene polymers: activation energies and reactions from room temperature to $100{ }^{\circ} \mathrm{C}$, Polym. Degrad. Stab. 121 (2015) 311-320.

[30] P. Xie, L. Wang, J. Zhang, Y. Hu, G. Luo, In situ removal of HBr via microdroplets for high selectivity bromobutyl rubber synthesis in a microreaction system, Ind. Eng. Chem. Res. 57 (2018) 10883-10892.

[31] S.M. Malmberg, J. Scott, D.A. Pratt, R.A. Whitney, Isomerization and elimination reactions of brominated poly(isobutylene-co-isoprene), Macromolecules 43 (2010) 8456-8461.

[32] P. Xie, K. Wang, P. Wang, Y. Xia, G. Luo, Synthesizing bromobutyl rubber by a microreactor system, Am. Inst. Chem. Eng. 63 (2016) 1002-1009.

[33] S. Jipa, M. Giurginca, T. Setnescu, R. Setnescu, G. Ivan, I. Mihalcea, Thermooxidative behaviour of halobutyl and butyl elastomers, Polym. Degrad. Stab. 54 (1996) 1-6.

[34] J.E.K. Schawe, Collected applications thermal analysis, Elastomers. 1 (2002) 38-44. Schwerzenbach.

[35] J.E.K. Schawe, Collected applications thermal analysis, Schwerzenbach, Elastomers 2 (2002), 24, 30-31. 